OPEN ACCESS

Edited by:

Qi Chen,

The University of Auckland

New Zealand

Reviewed by:

Surendra Sharma,

Women \& Infants Hospital of Rhode

Island, United States

Yi Zhang,

University of Auckland, New Zealand

${ }^{*}$ Correspondence:

Ying Chen

yingchen8@163.com

Specialty section:

This article was submitted to

Reproduction,

a section of the journal

Frontiers in Physiology

Received: 01 February 2021

Accepted: 12 April 2021

Published: 30 April 2021

Citation:

Chen A, Yu R, Jiang S, Xia Y and Chen Y (2021) Recent Advances of MicroRNAs, Long Non-coding RNAs, and Circular RNAs

in Preeclampsia.

Front. Physiol. 12:659638. doi: 10.3389/fphys.2021.659638

\section{Recent Advances of MicroRNAs, Long Non-coding RNAs, and Circular RNAs in Preeclampsia}

\author{
Ailing Chen ${ }^{1}$, Renqiang $Y_{u^{2}}$, Shiwen Jiang ${ }^{3}$, Yankai Xia ${ }^{4}$ and Ying Chen ${ }^{1 *}$ \\ 'Translational Medicine Laboratory, Research Institute for Reproductive Health and Genetic Diseases, The Affiliated Wuxi \\ Maternity and Child Health Care Hospital of Nanjing Medical University, Wuxi, China, ${ }^{2}$ Department of Neonatology, \\ The Affiliated Wuxi Maternity and Child Health Care Hospital of Nanjing Medical University, Wuxi, China, ${ }^{3}$ Research Institute \\ for Reproductive Health and Genetic Diseases, The Affiliated Wuxi Maternity and Child Health Care Hospital of Nanjing \\ Medical University, Wuxi, China, ${ }^{4}$ State Key Laboratory of Reproductive Medicine, Institute of Toxicology, Nanjing Medical \\ University, Nanjing, China
}

Preeclampsia is a clinical syndrome characterized by multiple-organ dysfunction, such as maternal hypertension and proteinuria, after 20 weeks of gestation. It is a common cause of fetal growth restriction, fetal malformation, and maternal death. At present, termination of pregnancy is the only way to prevent the development of the disease. Non-coding RNAs, including microRNAs, long non-coding RNAs, and circular RNAs, are involved in important pathological and physiological functions in life cycle activities including ontogeny, reproduction, apoptosis, and cell reprogramming, and are closely associated with human diseases. Accumulating evidence suggests that noncoding RNAs are involved in the pathogenesis of preeclampsia through regulation of various physiological functions. In this review, we discuss the current evidence of the pathogenesis of preeclampsia, introduce the types and biological functions of noncoding RNA, and summarize the roles of non-coding RNA in the pathophysiological development of preeclampsia from the perspectives of oxidative stress, hypoxia, angiogenesis, decidualization, trophoblast invasion and proliferation, immune regulation, and inflammation. Finally, we briefly discuss the potential clinical application and future prospects of non-coding RNA as a biomarker for the diagnosis of preeclampsia.

Keywords: preeclampsia, microRNAs, long non-coding RNAs, circular RNAs, trophoblast, biological function

Abbreviations: $3^{\prime}$, UTR $3^{\prime}$ untranslated region; AT1-AA, agonistic autoantibodies against the angiotensin II type 1 receptor; BHLHE40, basic helix-loop-helix family member e40; CCAT1, Colon cancer-related transcription factor 1; CDK, cyclin D-dependent kinases; ceRNA, competitive endogenous RNA; circRNA, circular RNA; dMSCs, decidualderived mesenchymal stem cells; EMT, epithelial-mesenchymal transition; FOXO1, forkhead box protein O1; HDAC4, histone deacetylase 4; HIF, hypoxia inducible factors; KCNQ1OT1, potassium voltage-gated channel subfamily Q member 1 overlapping transcript 1; LncRNA, long non-coding RNA; MALAT1, metastasis-associated lung adenocarcinoma transcript1; miRNA, microRNA; MMP, matrix metallo protein; MSCs, mesenchymal stem cells; ncRNA, non-coding RNA; PE, preeclampsia; PGK1, phosphoglycerate kinase 1; PGK1P2, phosphoglycerate kinase 1, pseudogene 2; PI3K, phosphatidylinositol 3-kinase; PIK3R2, phosphoinositide-3-Kinase Regulatory Subunit 2; ROCK1, Rho-associated coiledcoil kinase 1; sEng, soluble endothelin; sFlt-1, soluble fms-like tyrosine kinase 1; siRNA, interfering RNA; SPRY4-IT1, sprouty homolog 4 intronic transcript 1; THSD7A, thrombospondin type-1 domain-containing 7A; TUG1, taurine upregulated gene 1; VEGF, vascular endothelial growth factor. 


\section{INTRODUCTION}

Preeclampsia (PE) clinically manifests as new hypertension, proteinuria, or other clinical symptoms and signs of impaired end-organ function after 20 weeks of pregnancy (Duhig et al., 2018), and has an incidence of about 5-8\% (Souza et al., 2013). PE is divided into early-onset PE and late-onset PE by 34 weeks. Early-onset PE is widely acknowledged to have defective placentation in the early stages of pregnancy, while late-onset PE appears to be driven by oxidative changes in the placenta induced by a mismatch between normal maternal perfusion and fetoplacental demands, coupled with a maternal genetic predisposition to cardiovascular and metabolic disease (Burton et al., 2019) and/or a high BMI (McLaughlin et al., 2018). Compared with late-onset PE, early-onset PE usually has more severe complications (Lisonkova et al., 2014) and smaller placental perfusion fraction (Sohlberg et al., 2014). The pathophysiological characteristics of early-onset $\mathrm{PE}$ are due to shallow trophoblast invasion, which affects the remodeling of spiral arteries, resulting in decreased uterine placental blood flow and oxygenation, leading to increased placental oxidative stress. Late-onset PE is manifested as a result of villous overcrowding at term. Due to limited gas exchange and nutrient supply, cellular growth is competitively inhibited, which ultimately leads to placental oxidative stress (Salomon et al., 2017). Abnormal remodeling of the uterine spiral artery and damage to the systemic vascular endothelial system are key to the onset of PE. Insufficient reconstruction of the uterine spiral artery may be related to the following factors. First, in the maternal inflammatory response, a significant increase in the level of hypoxia-inducible factor (HIF) protein in the placenta of patients with $\mathrm{PE}$ indicates that hypoxia is a major risk factor for $\mathrm{PE}$ (Ali et al., 2019). Decreased placental perfusion and oxidative stress are key to stimulating the release of cytokines, antiangiogenic factors, and related downstream products. Eventually, inflammation and endothelial dysfunction of numerous organs and systems (including the vasculature, kidney, liver, and brain) have been observed in PE, especially early-onset PE (Kim et al., 2017). Second, vascular endothelial dysfunction is a possible factor, as the expression levels of soluble fms-like tyrosine kinase 1 (sFlt-1) and soluble endoglin (sEng) are elevated in the circulating blood and placenta tissue of patients with PE (Steegers et al., 2010). sFlt-1 and sEng are anti-angiogenic proteins that antagonize pro-angiogenic factors, including vascular endothelial growth factor (VEGF) and placental growth factor (PLGF), leading to placental vascular dysplasia (Steegers et al., 2010). Third, specific human leukocyte antigens on trophoblast cells in blood vessels may interact with natural killer cells and $\mathrm{T}$ cells of the maternal immune system, thereby altering the normal maternal-fetal immune tolerance (Wang X.Q. et al., 2018).

Non-coding RNA (ncRNA) can be transcribed from the genome but does not produce a functional protein, and can be divided into housekeeping and regulatory types. Housekeeping ncRNA includes ribosomal RNA, transfer RNA, and small nucleolar RNA, whereas regulatory ncRNA generally includes microRNA (miRNA), long non-coding RNA (lncRNA), and circular RNA (circRNA) (Gomes et al., 2013). lncRNA and
circRNA can share the miRNA response elements of linear messenger RNA (mRNA). They competitively bind to miRNA, thereby affecting the regulatory function and gene expression of miRNA (Lukiw, 2013). The competitive endogenous RNA (ceRNA) hypothesis indicates that an interaction network exists among miRNA, lncRNA, circRNA, and mRNA. ncRNA is not a so-called junk product but rather plays important biological roles in cell physiology, development, and metabolism. It can regulate transcription and post-transcriptional gene expression levels in various diseases (Yoon et al., 2013). Whether all transcripts are functional remains controversial, but it is clear that a large number of ncRNAs have functions. These functional ncRNAs are of great significance for the maintenance of normal cell functions as well as the occurrence and development of abnormal biological functions, and can regulate epigenetic inheritance, transcription, and post-transcriptional biological processes, in addition to participating in the regulation of multiple signaling pathways underlying cellular processes.

Whole-genome analysis of placenta-derived miRNA, lncRNA, and circRNA led to the identification of abnormally expressed ncRNAs associated with PE. Studies have confirmed that ncRNAs play important roles in regulating the development and function of the placenta and the pathogenesis of PE. The abnormal placental transcriptome of PE is affected by both genetic and epigenetic pathways. However, how differentially expressed genes and transcripts regulate the occurrence and development of PE has not been fully elucidated. In this review, we summarize recent advances of research into ncRNAs (including miRNAs, lncRNAs, and circRNAs) in the pathogenesis of PE.

\section{MiRNAs IN PE}

\section{MiRNAs}

MicroRNA is single-stranded RNA with a length of 22-28 nt, and is formed from a miRNA precursor with a hairpin ring structure through the sequential activities of the Drosha and Dicer ribonuclease III endonucleases. miRNA is conserved evolutionarily, and its expression shows tissue and stage specificity. It is an important element in physiological and pathological processes in various cells. miRNA affects the stability of target genes and inhibits the expression of target proteins. Mature miRNA binds to an RNA-induced silencing complex (RISC), and then specifically binds to the target RNA, causing its degradation. In animal cells, most miRNAs are not completely complementary to their target genes. The seed region of miRNA is complementary to the $3^{\prime}$ untranslated region ( $3^{\prime}$ UTR) of the target gene to prevent transcription (Djuranovic et al., 2011). miRNA is involved in a broad range of life processes including cell proliferation, differentiation, apoptosis, and migration (Sun and Lai, 2013). It has been speculated that miRNA regulates one third of human genes. During pregnancy, miRNA is involved in regulating the initiation of pregnancy and ensuring stability throughout pregnancy through the regulation of inflammation, immune tolerance, angiogenesis, apoptosis, and other processes (Schjenken et al., 2016). 


\section{MiRNAs in the Pathogenesis of PE}

Abnormally expressed miRNAs in the placenta participate in the occurrence and development of PE in terms of maternal-fetal hypoxia, angiogenesis, immunity, and inflammation through different cellular pathways and modes of action. Chim et al. (2008) first reported the presence of miRNA in the circulating blood of pregnant women. In a panel of TaqMan microRNA Analyses for 157 well-established miRNAs, they found that 17 occurred at concentrations $>10$-fold higher in the placentas than in maternal plasma and were undetectable at the end of pregnancy. The expression levels of multiple miRNAs such as miR-517-5p and miR-520a-5p in the circulating blood of patients with PE in early pregnancy are elevated, which consistent with those in the placenta of pregnant women with PE (Hromadnikova et al., 2013). Table 1 shows differential expression of miRNA involved in PE pathophysiology.

\section{Oxidative Stress and Hypoxia Damage}

During pregnancy, the production of reactive oxygen species (ROS) in the serum of pregnant women increases due to the normal systemic inflammatory response (Yang et al., 2012). Vascular remodeling disorders in PE lead to decreased placental perfusion and oxygenation, intensifying oxidative stress associated with the production of ROS and toxic lipid peroxides (Myatt, 2010). In pregnant women with PE, miR-335-5p is significantly up-regulated. ROS can increase the expression level of miR-335-5p in trophoblasts in a p53-dependent manner, leading to down-regulation of Sp1 and subsequent inhibition of the epithelial-mesenchymal transition (EMT) and cell migration (Lu et al., 2020). Compared with gestational week-matched controls, the circulating level of miR-195 was reduced in pregnant women with $\mathrm{PE}$, and the expression levels of FADdependent oxidoreductase domain containing 1 (FOXRED1) and pyruvate dehydrogenase phosphatase regulatory subunit (PDPR) in the placenta were significantly elevated. Under chronic hydrogen peroxide stimulus, miR-195 expression decreased. miR-195 could suppress mitochondrial energy production via targeting of FOXRED1 and PDPR, which led to trophoblast cell apoptosis under oxidative stress (Wang H. et al., 2018). Perfluorooctanesulfonic acid, which induces oxidative stress, significantly increases miR29-b during the pathogenesis of PE (Sonkar et al., 2019).

The initial stage of placenta formation occurs in a relatively hypoxic environment. This environment can promote trophoblast cell invasion and blood vessel formation. However, continuous hypoxia leads to abnormal trophoblast differentiation and insufficient invasion, resulting in uterine spiral artery recasting disorders and decreased placental blood perfusion. Eventually, the angiogenetic function of the placenta becomes abnormal (Berkane et al., 2007). miR-210 is an important hypoxia sensor regulated by Hipper-Lindau tumor suppressor genes, HIF- $1 \alpha$, HIF- $2 \alpha$, and the inducible factor prolyl hydroxylase (Seyom et al., 2015). miR-210 is significantly elevated in PE plasma and placenta, which is associated with cell migration, vascular remodeling, and growth during embryo formation (Zhao et al., 2016). Patients with mild or severe PE have about four or ten times the level of miR-210 in the plasma relative to healthy people, respectively ( $\mathrm{Wu}$ et al., 2015). Under hypoxic conditions, miR-210 expression in trophoblasts is significantly up-regulated. Histopathological results show that high expression of miR-210 can lead to down-regulation of HSD17B1 and E2 levels (Song et al., 2015), while low expression of miR-210 can lead to down-regulation of PTPN2 in the PDGFR-Akt pathway and thus promote cell proliferation, migration, and invasion (Li J. et al., 2019). 17- $\beta$ hydroxylase is the receptor of miR-210, and is mainly expressed in placental syncytiotrophoblasts. Its level falls significantly before PE occurrence. Sorting nexin 16 (SNX16) plays a negative regulatory role in cell migration and tumorigenesis. The expression of miR-196a-5p is reduced in the PE placenta, while the expression of SNX16 is increased (Zhang L. et al., 2013). Up-regulation of miR-196a-5p can inhibit SNX16 expression. Luciferase reporter gene analysis has shown that miR-196a-5p binds to the $3^{\prime}$ UTR of SNX16 mRNA. An increase of miR-196a-5p or knockdown of SNX16 can restore cell viability, migration, invasion, and expression of matrix metalloprotein 2 (MMP-2) and MMP-9 under hypoxic conditions. Furthermore, BHLHE40 binds to the promoter of the miR-196a-5p gene. BHLHE40 knockdown alleviated $\mathrm{PE}$ symptoms in pregnant C57/BL6N mice, suggesting that the BHLHE40/miR-196a-5p/SNX16 axis is involved in the pathogenesis of PE (Zhang L. et al., 2013).

Among hypoxia-related miRNAs, miR-141 (Wu D. et al., 2019), miR-517 (Anton et al., 2015), miR-218, and their host genes slit guidance ligand 2 (SLIT2) and SLIT3 have elevated expression levels in placental tissues of patients with $\mathrm{PE}$ (Fang et al., 2017). miR-141 down-regulates the expression of MMP-2, p62, and microtubule-associated protein 1A/1Blight chain 3 (LC3B) in HTR-8/SVneo cells by targeting the $\mathrm{C}-\mathrm{X}-\mathrm{C}$ motif chemokine ligand $12 \beta$ (CXCL12 $\beta$ ) gene, while also up-regulating Rho-associated coiled-coil containing protein kinase 1 (ROCK1) and Ras homolog family member A (RhoA) expression, promoting the apoptosis of HTR-8/SVneo cells and inhibiting their invasion and vascularization abilities (Wu D. et al., 2019). In vitro cell experiments indicate that hypoxia can induce high expression of miR-218, which is down-regulated after HIF-1 $\alpha$ gene knockout. Chromatin immunoprecipitation results suggest that HIF-1 $\alpha$ can directly bind to the promoters of SLIT2 and SLIT3. Further studies have shown that miR-218 targets LIM and $\mathrm{SH} 3$ protein 1 (LASP1), thereby inhibiting the infiltration of trophoblast cells, which may eventually induce the onset of $\mathrm{PE}$ (Fang et al., 2017). Hypoxia affects the expression of miR-145$5 \mathrm{p}$, which is down-regulated in the PE placenta. Low expression of miR-145-5p inhibits the activity and invasiveness of HTR8/SVneo cells, whereas overexpression of miR-145-5p promotes these effects. Furthermore, research suggests that FLT1 is the target gene of miR-145-5p (Lv et al., 2019).

\section{Regulation of Angiogenesis Factors and Promotion of Vascular Endothelial Damage}

Angiogenesis plays a key role in tissue repair and organ growth, and an imbalance of angiogenesis can easily lead to the occurrence and development of PE (Zhang M. et al., 2016). The dynamic balance between vasodilator and contractile factors, such as VEGF and its receptor sFlt-1 (Zhu et al., 2009), PLGF 
TABLE 1 | miRNAs in the pathogenesis of Preeclampsia.

\begin{tabular}{|c|c|c|c|c|c|}
\hline miRNAs & Source & Expression & Target & Function & References \\
\hline miR-106b & $\begin{array}{l}\text { Placental tissues and peripheral } \\
\text { blood mononuclear cells }\end{array}$ & upregulated & MMP-2 & invasion and proliferation & $\begin{array}{l}\text { Li et al., 2017c; Eghbal-Fard et al., } \\
2019\end{array}$ \\
\hline $\operatorname{miR}-126$ & $\begin{array}{l}\text { Placental tissues and } \\
\text { endothelial progenitor cells }\end{array}$ & downregulated & PIK3R2 & $\begin{array}{l}\text { proliferation, differentiation, } \\
\text { migration and vascular sprouting }\end{array}$ & Yan et al., 2013 \\
\hline miR-128a & Placental tissues & upregulated & Bax & apoptosis & Ding et al., 2016 \\
\hline miR-133 & Placental tissues & upregulated & $\begin{array}{c}\text { Rho/ROCK } \\
\text { signaling pathway }\end{array}$ & apoptosis & Zhang W.M. et al., 2019 \\
\hline miR-136 & $\begin{array}{l}\text { MSCs, exosomes of peripheral } \\
\text { blood and umbilical cord } \\
\text { mesenchymal stem cells }\end{array}$ & upregulated & BCL2, VEGF & $\begin{array}{l}\text { suppress proliferation and promote } \\
\text { apoptosis of MSCs }\end{array}$ & Ji et al., 2017; Motawi et al., 2018 \\
\hline miR-141 & $\begin{array}{l}\text { Placental tissues, peripheral } \\
\text { blood }\end{array}$ & upregulated & $\begin{array}{l}\text { CXCL12 } \beta, \text { MMP-2, } \\
\text { p62, LC3B, } \\
\text { ROCK1, RhoA, } \\
\text { EG-VEGF }\end{array}$ & $\begin{array}{l}\text { apoptosis, invasion and } \\
\text { vascularization }\end{array}$ & $\begin{array}{l}\text { Wang C.Y. et al., 2019; Wu J.L. } \\
\text { et al., } 2019\end{array}$ \\
\hline miR-141-3p & HUVECS & upregulated & Notch2 & $\begin{array}{l}\text { tube formation, migration, invasion } \\
\text { and apoptosis }\end{array}$ & Ling et al., 2021 \\
\hline miR-145-5p & $\begin{array}{l}\text { Placental tissues and umbilical } \\
\text { cord blood }\end{array}$ & downregulated & FLT1, Cyr61 & trophoblast viability and invasion & $\begin{array}{l}\text { Hromadnikova et al., 2017; Wen } \\
\text { et al., 2018; Lv et al., 2019; } \\
\text { Wang Y. et al., } 2019\end{array}$ \\
\hline miR-155 & $\begin{array}{l}\text { Placental tissues and maternal } \\
\text { plasma }\end{array}$ & upregulated & eNOS & invasion and migration & Li et al., 2014; Gan et al., 2017 \\
\hline $\mathrm{miR}-16$ & Placental tissues & upregulated & Notch2 & proliferation, migration and invasion & Yuan et al., 2020 \\
\hline $\operatorname{miR}-17$ & Placental tissues & upregulated & $\begin{array}{l}\text { ephrin-B2/Eph-B4 } \\
\text { receptor }\end{array}$ & angiogenesis & Wang et al., 2012 \\
\hline miR-181a-5p & $\begin{array}{l}\text { Placental tissues and maternal } \\
\text { plasma }\end{array}$ & upregulated & IGF2BP2 & $\begin{array}{l}\text { Invasion, proliferation, apoptosis } \\
\text { and migration }\end{array}$ & $\begin{array}{l}\text { Wu et al., 2018; Huang et al., 2019; } \\
\text { Gusar et al., } 2020\end{array}$ \\
\hline miR-196a-5p & Placental tissues & downregulated & SNX16, BHLHE40 & $\begin{array}{l}\text { trophoblast viability, migration, and } \\
\text { invasion }\end{array}$ & Zhang L. et al., 2013 \\
\hline miR-203 & $\begin{array}{l}\text { Placental tissues and maternal } \\
\text { vessel }\end{array}$ & upregulated & VEGFA & proliferation, migration and invasion & $\begin{array}{l}\text { Wang Y. et al., 2016; Liu et al., } \\
2018\end{array}$ \\
\hline miR-205 & $\begin{array}{l}\text { Placental tissues and maternal } \\
\text { plasma }\end{array}$ & upregulated & MED1 & cell differentiation & $\begin{array}{l}\text { Mouillet et al., 2010; Yang et al., } \\
2015\end{array}$ \\
\hline miR-20a & Placental tissues & upregulated & FOXA1 & proliferation, migration and invasion & $\begin{array}{l}\text { Wang Y. et al., 2014; Yuan et al., } \\
2020\end{array}$ \\
\hline $\mathrm{miR}-20 \mathrm{~b}$ & Placental tissues & upregulated & MMP-2, MCL-1 & proliferation, migration and invasion & $\begin{array}{l}\text { Jin et al., 2017; Zhang S.S. et al., } \\
2020\end{array}$ \\
\hline miR-210 & $\begin{array}{l}\text { Placental tissues and maternal } \\
\text { plasma }\end{array}$ & upregulated & $\begin{array}{c}\text { HIF-1a, HIF-2 } \alpha \text {, } \\
\text { HSD17B1, E2, } \\
\text { PTPN2, KCMF1, } \\
\text { THSD7A, NOTCH1 }\end{array}$ & $\begin{array}{l}\text { proliferation, migration apoptosis } \\
\text { and invasion, vascular remodeling } \\
\text { and growth, tube-like formation } \\
\text { capabilities }\end{array}$ & $\begin{array}{l}\text { Ishibashi et al., 2012; Zhang et al., } \\
\text { 2012; Luo et al., 2014; Seyom } \\
\text { et al., 2015; Song et al., 2015; Wu } \\
\text { et al., 2015; Luo et al., 2016; Zhao } \\
\text { et al., 2016; Li J. et al., 2019; } \\
\text { Wang R. et al., } 2019\end{array}$ \\
\hline$m i R-214-5 p$ & Placental tissues & upregulated & Jagged 1/Notch & proliferation, migration and invasion & Gong et al., 2020a \\
\hline miR-218 & Placental tissues & upregulated & LASP1 & invasion & Fang et al., 2017 \\
\hline$m i R-218-5 p$ & Placental tissues & downregulated & TGFB2 & invasion and differentiation & Brkic et al., 2018 \\
\hline miR-299 & Placental tissues & upregulated & HDAC2 & invasion and migration & Gao et al., 2018 \\
\hline miR-29b & Placental tissues and dMSCs & upregulated & $\begin{array}{l}\text { MCL1, MMP-2, } \\
\text { VEGFA, } \\
\text { ITGB1,HDAC4, }\end{array}$ & $\begin{array}{l}\text { apoptosis, invasion, angiogenesis, } \\
\text { proliferation, migratory and tubule } \\
\text { formation }\end{array}$ & Li et al., 2013; Xin et al., 2017 \\
\hline $\operatorname{miR}-30 a-3 p$ & Placental tissues & upregulated & IGF-1 & invasion and apoptosis & Lu et al., 2020 \\
\hline miR-335-5p & Placental tissues & upregulated & ROS/p53, Sp1 & migration and EMT & Jiang et al., 2015; Lu et al., 2020 \\
\hline $\operatorname{miR}-342-3 p$ & $\begin{array}{l}\text { Placental tissues and maternal } \\
\text { plasma }\end{array}$ & upregulated & ID4, PDGFRA & $\begin{array}{l}\text { cell viability, apoptosis and invasion, } \\
\text { proliferation, migration, and } \mathrm{G} 1 / \mathrm{S} \\
\text { phase transition }\end{array}$ & $\begin{array}{l}\text { Wu et al., 2012; Yang and Guo, } \\
\text { 2019; Han et al., } 2020\end{array}$ \\
\hline miR-346 & $\begin{array}{l}\text { Placental tissues and maternal } \\
\text { plasma }\end{array}$ & upregulated & LRP6 & proliferation, migration and invasion & $\begin{array}{l}\text { Tsai et al., 2017; Zhang L. et al., } \\
2020\end{array}$ \\
\hline miR-376c & $\begin{array}{l}\text { Placental tissues and maternal } \\
\text { plasma }\end{array}$ & downregulated & $\begin{array}{l}\text { ALK5, ALK7, } \\
\text { TGF-b/Nodal }\end{array}$ & proliferation, migration and invasion & Fu et al., 2013 \\
\hline
\end{tabular}


TABLE 1 | Continued

\begin{tabular}{|c|c|c|c|c|c|}
\hline miRNAs & Source & Expression & Target & Function & References \\
\hline miR-378a-5p & Placental tissues & downregulated & Nodal & $\begin{array}{l}\text { cell growth, survival, migration and } \\
\text { invasion }\end{array}$ & Luo et al., 2012 \\
\hline $\operatorname{miR}-454$ & Placental tissues & downregulated & $\begin{array}{l}\text { Nodal/ALK7, } \\
\text { EPHB4 }\end{array}$ & proliferation and invasion & Shi et al., 2019 \\
\hline miR-494 & dMSCs & upregulated & $\begin{array}{l}\text { CDK6, CCND1, VE } \\
\text { Wang R. et al., } \\
2019 \text { GF }\end{array}$ & $\begin{array}{l}\text { arrests G1/S transition, migration } \\
\text { and impairs HUVEC capillary } \\
\text { formation }\end{array}$ & Chen S. et al., 2015 \\
\hline miR-495 & $\begin{array}{l}\text { Umbilical cord tissue and } \\
\text { dMSCs }\end{array}$ & upregulated & - & $\begin{array}{l}\text { cell cycle, apoptosis, migration, } \\
\text { invasion and tube formation }\end{array}$ & Li et al., 2017b \\
\hline $\operatorname{miR}-517$ & $\begin{array}{l}\text { Placental tissues and maternal } \\
\text { plasma }\end{array}$ & upregulated & $\begin{array}{l}\text { sFLT1, } \\
\text { ERK/MMP-2 } \\
\text { pathway }\end{array}$ & proliferative and invasive & $\begin{array}{l}\text { Anton et al., 2015; Fu et al., 2018; } \\
\text { Hromadnikova et al., } 2019\end{array}$ \\
\hline miR-520g & Maternal serum & upregulated & MMP-2 & migration and invasion & Jiang et al., 2017 \\
\hline miR-646 & $\begin{array}{l}\text { Human peripheral } \\
\text { blood-derived endothelial } \\
\text { progenitor cells }\end{array}$ & upregulated & VEGF-A, HIF-1 $1 \alpha$ & $\begin{array}{l}\text { differentiation, migration, } \\
\text { angiogenesis }\end{array}$ & Dong X. et al., 2020 \\
\hline
\end{tabular}

(secreted by placental trophoblasts), and endothelin, can promote the growth, differentiation, migration, and infiltration of blood vessels in the placenta and decidua, and maintain vascular intima integrity and placental vascular permeability.

miR-126 is a powerful miRNA related to angiogenesis. miR126 expression decreases in pregnant women with $\mathrm{PE}$, which is positively correlated with the degree of placental ischemia in PE. Blood flow can activate zinc finger transcription factors to induce miR-126 expression (Yan et al., 2013). An imbalance of angiogenic factors in $\mathrm{PE}$, including a decrease of pro-angiogenic factor VEGF-A and increase in hypoxia, lead to reductions of miR-126 expression and endothelial cell numbers (Yan et al., 2013). Hong et al. (2014) showed that miR-126 was underexpressed in the placenta tissues of patients with PE based on quantitative reverse transcription polymerase chain reaction (qRT-PCR), and was positively correlated with VEGF mRNA expression. In addition, miR-126 and miR-378 target tumor suppressor candidate 2 (TUSC2) to up-regulate pro-angiogenic factors; therefore, low expression levels of these two miRNAs in PE may lead to spiral artery remodeling disorder, placental ischemia, hypoxia, and hypoperfusion (Weber et al., 2016). Studies on the pathway of miR-126/PIK3R2/PI3K/AKT cells indicate that the $3^{\prime}$ UTR of miR-126 targets and regulates phosphoinositide-3-kinase regulatory subunit 2 (PIK3R2), which is an important component of the VEGF pathway. After miR126 activation, PIK3R2 expression decreases, while the mRNA and protein levels of phosphoinositide 3-kinase (PI3K) and protein kinase B (AKT) increase (Zhu et al., 2009), which further illustrates the important role of miR-126 that promotes angiogenesis and anti-apoptotic mechanisms, suggesting its potential function in the pathogenesis of $\mathrm{PE}$.

The survival of mesenchymal stem cells (MSCs) and angiogenesis at the maternal-fetal interface are essential factors for a successful pregnancy. miR-136 is highly expressed in MSCs derived from PE decidua. High levels of miR-136 can inhibit the proliferation of MSCs and promote the apoptosis of MSCs by targeting BCL2, and can impair human umbilical vein endothelial cell (HUVEC) capillary formation and trophoblast cell invasion by inhibiting VEGF (Ji et al., 2017). In addition, the expression level of miR-29b increases in decidua-derived mesenchymal stem cells (dMSCs) of severe PE patients, and overexpression of miR-29b targets histone deacetylase 4 (HDAC4) to reduce the proliferation ability of dMSCs, as well as the migration and tubule-formation abilities of HUVECs (Xin et al., 2017). Expression of miR-495 increased in the umbilical cord tissue and MSCs of patients with pregnant women with severe PE ( $\mathrm{Li}$ et al., 2017b). Further studies confirmed that miR-495 targets BMI-1 to promote cell apoptosis, inhibit the migration and invasion of trophoblasts, and hinder tubule formation by HUVECs.

\section{Roles in Trophoblast Cell Invasion}

Trophoblasts are the main cell type of the placenta and are involved in the formation of the placenta. miR-210 not only influences trophoblast invasion by adapting to oxidative stress but also directly affects cell invasion by targeting specific cell invasion markers. In PE placentas, the thrombospondin type 1 domain containing 7A (THSD7A) level is significantly downregulated and inversely proportional to the level of miR-210. Hypoxia significantly increases miR-210 expression and inhibits THSD7A expression in a time-dependent manner, confirming that THSD7A inhibits the invasion of miR-210 into HTR8/SVneo cells (Luo et al., 2016). In another study, up-regulation of miR-210 reduced Notch1 expression; impaired HTR8/SVneo proliferation, migration, invasion, and tubule formation; and promoted apoptosis; down-regulation of miR-210 had the opposite effects. These findings suggest that miR-210 plays a role in trophoblast dysfunction by reducing Notch1 expression (Wang R. et al., 2019).

As shown by microarray analysis, miR-49 is highly expressed in dMSCs in PE. miR-494 prevents the G1/S transition of dMSCs by targeting cyclin dependent kinase 6 (CDK6) and cyclin D1 (CCND1). The supernatant of miR-494-overexpressing dMSCs reduces the migration of HTR-8/SVneo cells and impedes the formation of HUVEC capillaries by inhibiting VEGF (Chen S. et al., 2015). In situ hybridization demonstrated that the level of miR-20a was higher in PE than in normal placental tissue, 
and showed that the up-regulation of miR-20a can inhibit the proliferation, migration, and invasion of trophoblast cells by inhibiting the expression of forkhead box A1 (FOXA1) (Wang Y. et al., 2014). In addition, miR-646 expression is elevated in endothelial progenitor cells isolated from the peripheral blood of pregnant women with PE (Dong D. et al., 2020). miR-646 reduces angiogenesis and inhibits the proliferation, differentiation, and migration of endothelial progenitor cells by down-regulating VEGF-A and HIF-1 $\alpha$ expression.

\section{Roles in Immune Regulation and Inflammation}

As a powerful tool for post-transcriptional regulation, microRNAs not only participate in the pathological process of $\mathrm{PE}$ through oxidative stress, hypoxia damage, vascular endothelial damage, and regulating the biological functions of trophoblast cells, but also regulate the immune response. In a healthy pregnancy, proper immune regulation prevents excessive systemic inflammation. In PE, abnormal activation of decidual $\mathrm{T}$ cells, uterine natural killer cells, macrophages (Faas and De Vos, 2018), and the imbalanced differentiation of helper $\mathrm{T}$ cell subsets destroy normal maternal-fetal immune tolerance. The activation of immune cells and subsequent secretion of cytokines affect angiogenesis, trophoblast invasion, and spiral artery remodeling, which is considered to be an indirect cause of insufficient reconstruction of the uterine spiral artery (Geldenhuys et al., 2018). MiR-223 was down-regulated in the placenta and circulating samples of pregnant women with PE (Sheikh et al., 2016). Shi et al. (2013) showed that after miR-223 knockout, the expression of immune and inflammation-related genes in mice changes significantly, with the number of immune $\mathrm{T}$ cells decreasing and the fetus-to-placenta mass ratio gradually decreasing as pregnancy progresses. After the female mouse reproductive tract comes into contact with semen, the expression of miR-223 is up-regulated. In contrast, down-regulation of miR-223 expression has an adverse effect on immune tolerance in female mice. Therefore, after maternal exposure to semen containing foreign antigens, miR-223 can increase maternal immune tolerance and foster pregnancy. In addition, studies of the IL-6/miR-223/STAT3 cell pathway suggest that downregulation of miR-223 expression can lead to activation of signal transducer and activator of transcription 3 (STAT3), which is accompanied by pro-inflammatory production of the cytokine interleukin 6 (IL-6). Enhanced IL-6 expression can reduce miR-223 levels, leading to vascular dysfunction and promoting macrophage infiltration, with adverse effects on the invasion of cytotrophoblast cells into the decidua and myometrium (Lockwood et al., 2008). Immunohistochemistry has further demonstrated that the decidua and trophoblast cells of patients with PE exhibit high expression of IL-6 (Lockwood et al., 2008), which is the main factor inducing decreased miR-223 expression Dong D. et al. (2020). Low expression of miR-223 in PE may be a compensatory mechanism that activates endothelial function and increases angiogenesis. Down-regulation of miR-223 increases the expression of $\beta 1$ integrin and promotes angiogenesis (Shi et al., 2013). Ischemia and hypoxic stress can target the upstream promoter of miR-223 CCAAT enhancer binding protein alpha
$(\mathrm{C} / \mathrm{EBP}-\alpha)$ through HIF protein, thereby reducing the miR-223 level (Seifeddine et al., 2008).

Inflammation-related miR-125b is up-regulated in placental tissues and serum of PE patients. Sphingosine-1-phosphate lyase1 (SGPL1) is a target gene of miR-125b. miR-125b down-regulates SGPL1 expression and enhances IL- 8 production, which can be reversed by abolishing the overexpression of SGPL1. Therefore, miR-125b can increase IL-8 expression in PE, which in turn induces maternal inflammation (Yang et al., 2016). Kopriva et al. (2013) suggested that high expression of miR-210 in the placenta of patients with PE is related to inflammatory factors, and that the appearance of inflammation is related to overactivation of toll-like receptor 3 (TLR3) (Bugge et al., 2017). TLR3 is activated in patients with PE (Chatterjee et al., 2012); by activating HIF- $1 \alpha$ and NF- $\mathrm{Bp} 50$, TLR3 induces the upregulation of miR-210 and further down-regulates the target gene signal transducer and STAT6. miR-155 can enhance the AP$\mathrm{A} / \mathrm{NK}-\mathrm{kB}$ inflammatory response pathway by regulating cyclin D1, which targets interleukin 1 receptor associated kinase 3 (IRAKM), NFKB inhibitor interacting Ras like 1 (NKIRAS1), and phosphatase and tensin homolog (PTEN), suggesting that miR-155 is related to superficial implantation in spiral arteries, a characteristic of PE (Xue et al., 2013).

In general, Each miRNA has multiple target genes, such as miR-210, which not only targets HSD17B1s (Song et al., 2015), but also targets PTPN2 (Li J. et al., 2019), KCMF1 (Luo et al., 2014), THSD7A (Tian et al., 2020), and Notch1 (Wang R. et al., 2019) to regulate the biological function of trophoblast and participate in vascular remodeling, growth and tube formation. Besides, several miRNAs also target the same gene. MMPs are important regulators of vascular and uterine remodeling. Decreased vascular MMP-2 may lead to the decrease of vasodilation, the enhancement of vasoconstriction, hypertensive pregnancy, and PE (Chen and Khalil, 2017). miR141 (Wu D. et al., 2019) and miR-520g (Jiang et al., 2017) down-regulate the expression of MMP-2 and participate in the pathogenesis of PE by inhibiting angiogenesis and the migration, invasion, proliferation of trophoblast. This complex regulatory network not only regulates the expression of multiple genes through one miRNA, but also fine-tunes the expression of specific genes through cooperation of several miRNAs.

\section{LncRNA IN PE}

\section{LncRNA}

Long non-coding RNA is commonly present in eukaryotic cells. Defined by a length of more than 200 nucleotides and lack of open reading frames, lncRNA can regulate gene expression at the epigenetic, transcriptional, and post-transcriptional levels (Sun and Kraus, 2015), and its proportion exceeds $80 \%$ of total RNA (Guttman and Rinn, 2012). Most lncRNAs are produced through transcription by RNA polymerase II, and their sources are diverse. They can be produced due to the destruction of gene structures encoding proteins, or through rearrangement of two separate untranslated chromosomes to produce a lncRNA containing multiple exons. According to 
the genomic location of lncRNAs, they can be roughly divided into five categories: sense lncRNA, antisense lncRNA, intragenic lncRNA, intergenic lncRNA, and bidirectional lncRNA. IncRNAs are important cis- and trans-regulators of gene activity, but their expression is primarily cis-acting, often reflecting the expression of neighboring genes. The expression and function of lncRNAs have tissue and spatiotemporal specificities, and play important roles in many life processes, such as chromatin modification, dose compensation effects, epigenetics, cell cycle, cell differentiation, transcription, and post-transcriptional regulation (Delas and Hannon, 2017). Their main regulation methods include acting as an activator or inhibitor of the transcript via coordinated interactions with the RNA-binding protein or regulation of the promoter of the targeted protein; forming an RNA-DNA complex to prevent the binding of transcripts; regulating DNA methylation or modifying histones; and forming complexes with proteins that affect the positioning of those proteins. IncRNA can also act as a miRNA sponge through base pairing and formation of the RISC, which reduces the activities of these small RNA molecules and inhibits the expression of miRNA-targeted genes (Guo et al., 2014).

\section{LncRNAs in the Pathogenesis of PE}

Long non-coding RNA have emerged as critical molecular regulators in biological processes and diseases, such as cancer, Alzheimer's disease, and cardiovascular disease. Recently, many groups have indicated that abnormally expressed lncRNAs in the placenta and circulating blood of pregnant women with $\mathrm{PE}$ participate in the pathophysiological process of $\mathrm{PE}$ by regulating the biological functions of trophoblasts, angiogenesis, decidualization, and inflammation. Table 2 shows the differential expression of lncRNAs involved in PE pathophysiology.

\section{Roles of IncRNAs in Regulating the Invasion and Migration of Trophoblast Cells}

Trophoblast cells have invasion and migration characteristics like tumor cells. Insufficient infiltration of placental trophoblast cells and poor vascular remodeling are associated with pregnancyrelated complications, including recurrent miscarriage, PE, eclampsia, and intrauterine growth retardation. IncRNA MALAT-1 was firstly identified in lung cancer (Ji et al., 2003). The expression level of MALAT1 lncRNA was reduced in the placentas of PE patients. After silencing of MALAT1 in the trophoblast cell line JEG-3, the cell cycle was arrested in the G0/G1 phase; caspase 3, caspase 9 and poly(ADP-ribose) polymerase 1 (PARP-1) levels increased significantly; and cell invasion and migration were inhibited (Chen S. et al., 2015). Similarly, Li et al. (2020) observed low MALAT1 expression in the placenta of early-onset eclampsia patients. Based on the RNA sequence, Fos was identified as a downstream functional gene of MALAT1. MALAT1 promotes the migration and invasion of trophoblast cells via Fos-induced EMT. Silencing the expression of MALAT1 (-/-) inhibits the invasion and migration of trophoblast cells. MALAT1-/- also leads to reduced expression of $\mathrm{N}$-cadherin and vimentin, while the expression of E-cadherin is elevated, highlighting the role of MALAT1 in spiral artery remodeling damage during the placental pathogenesis of early eclampsia. Another study demonstrated that MALAT1 expression decreased in the placenta of pregnant women with PE, whereas miR-206 expression increased. A dual-luciferase reporter experiment verified the interactions of MALAT1 and miR-206, as well as miR-206 and insulin-like growth factor-1 (IGF-1). MALAT1 inhibits trophoblast cell migration and invasion by regulating the IGF-1/PI3K/Akt signaling pathway via miR-206 (Wu et al., 2020). MALAT-1 plays a key role in regulating the angiogenesis, vascularization of the maternal decidua and fetal umbilical vasculature. Expression of MALAT1 in umbilical cord tissues and MSCs of patients with severe PE are also reduced (Li et al., 2017a). Transfection of a MALAT1 plasmid into MSCs causes the cell cycle to enter the G2/M phase and inhibits apoptosis. The supernatant of MALAT1-overexpressing MSCs promotes MSC migration, HTR-8/SVneo cell invasion, and HUVEC tube formation, whereas silencing of MALAT1 has the opposite effects. Hydrogen peroxide reduces MALAT1 expression in MSCs in a dose-dependent manner, indicating that peroxide may cause down-regulation of MALAT1 expression (Li et al., 2017a). In general, low expression of MALAT1 in the placenta of PE affects the cell cycle, apoptosis, invasion, migration, spiral artery remodeling, and tube formation through different target molecules.

Long non-coding RNA KCNQ1 is an imprinted gene that expresses only paternal alleles. KCNQ1OT1 mRNA expression was reduced in PE placental tissues, while miR-146a-3p expression was increased. A dual-luciferase reporter gene experiment confirmed the targeting relationship between KCNQ1OT1 and miR-146a-3p. Silencing KCNQ1OT1 expression up-regulates miR-146a-3p expression; inhibits HTR8/SVneo cell proliferation, invasion, and migration; and prevents CXCL12/CXCR4 signaling pathway activation. Thus, inhibiting miR-146a-3p expression can attenuate KCNQ1OT1, regulating cellular proliferation, invasion, and migration abilities and inhibiting the CXCL12/CXCR4 signaling pathway. The KCNQ1OT1/miR-146a-3p/CXCL12/CXCR4 molecular system may act as a regulatory network in the pathogenesis of PE by affecting the function of trophoblast cells (Chen F.R. et al., 2020). $\mathrm{Yu}$ et al. (2018) found that IncRNA TUG1 was significantly down-regulated in PE placental tissue, which inhibited the migration and invasion of trophoblast-like cells. Bioinformatics and functional analysis show that TUG1 interacts with miR204-5p and negatively regulates the expression and function of miR-204-5p in trophoblast cells. TUG1 regulates the migration and invasion of trophoblasts through sponging of miR-2045 ; therefore, the TUG1/miR-204-5p axis may be a potential target for the intervention of PE. In another study, TUG1 was significantly reduced in the placentas of PE patients. Ectopic expression of TUG1 promotes cell proliferation, invasion, and angiogenesis, but has a negative regulatory effect on cell apoptosis. TUG1 can act as a molecular sponge of miR-29b, thereby regulating MCL1, VEGF-A, and MMP-2 during the development of PE (Li Q. et al., 2019). In addition, lncZBTB39 is up-regulated in the PE placenta, and its overexpression (downregulation) inhibits (enhances) invasion and migration of HTR8/SVneo cells and MMP-2 activity. lncZBTB39 negatively regulates the invasion and migration of trophoblast cells, and 
TABLE 2 | LncRNAs in the pathogenesis of Preeclampsia.

\begin{tabular}{|c|c|c|c|c|c|}
\hline IncRNAs & Source & Expression & Target & Function & References \\
\hline AGAP2-AS1 & Placental tissues & downregulated & miR-574-5p/JDP2 & $\begin{array}{l}\text { proliferation, invasion and } \\
\text { apoptosis }\end{array}$ & Xu et al., 2020 \\
\hline ATB & Placental tissues & downregulated & - & $\begin{array}{l}\text { migration, proliferation, and } \\
\text { tube formation }\end{array}$ & Liu X. et al., 2017 \\
\hline CCAT1 & Placental tissues & upregulated & D1-P16-CDK4 & $\begin{array}{l}\text { cell proliferation and cell } \\
\text { cycle }\end{array}$ & Deng et al., 2015 \\
\hline DC & Dendritic cells & upregulated & p-STAT3 & invasion & Zhang W. et al., 2017, 2020 \\
\hline EGFR-AS1 & Placental tissues & downregulated & EGFR-JAK/STAT & proliferation & Zhao and Jiang, 2018 \\
\hline \multirow[t]{2}{*}{$\mathrm{H} 19$} & Placental tissues & upregulated & $\mathrm{PI3K} / \mathrm{AKT} / \mathrm{mTOR}$ & $\begin{array}{l}\text { cell viability, invasion, } \\
\text { autophagy }\end{array}$ & Xu J. et al., 2018 \\
\hline & $\begin{array}{c}\text { Exosomes secreted } \\
\text { by MSCs }\end{array}$ & upregulated & microRNA let-7b/FOXO1 & $\begin{array}{l}\text { invasion, migration and } \\
\text { apoptosis }\end{array}$ & Chen Y. et al., 2020 \\
\hline HOTAIR & Placental tissues & upregulated & miR-106a/EZH2 & $\begin{array}{l}\text { proliferation, migration and } \\
\text { invasion }\end{array}$ & Zhao et al., 2020 \\
\hline HOTTIP & Placental tissues & downregulated & RND3 & $\begin{array}{l}\text { cell proliferation and cell } \\
\text { cycle }\end{array}$ & Li et al., 2018 \\
\hline KCNQ10T1 & Placental tissues & downregulated & $\begin{array}{l}\text { miR-146a- } \\
\text { 3p/CXCL12/CXCR4 }\end{array}$ & $\begin{array}{l}\text { proliferation, invasion and } \\
\text { migration }\end{array}$ & Chen Y. et al., 2020 \\
\hline Linc00261 & Placental tissues & upregulated & miR-558/TIMP4 & $\begin{array}{l}\text { invasion, migration and } \\
\text { apoptosis }\end{array}$ & Cheng et al., 2019b \\
\hline LINC00511 & Placental tissues & downregulated & miR-31-5p/HOXA7 & $\begin{array}{l}\text { proliferation, invasion and } \\
\text { autophagy }\end{array}$ & Dong X. et al., 2020 \\
\hline IncRNA uc. 187 & Placental tissues & upregulated & - & $\begin{array}{l}\text { proliferation, invasion and } \\
\text { apoptosis }\end{array}$ & Cao et al., 2017 \\
\hline IncZBTB39 & Placental tissues & upregulated & miR-210/THSD7A & invasion and migration & Tian et al., 2020 \\
\hline \multirow[t]{4}{*}{ MALAT1 } & Placental tissues & downregulated & - & $\begin{array}{l}\text { proliferation, migration } \\
\text { invasion and apoptosis }\end{array}$ & Chen H. et al., 2015 \\
\hline & Placental tissues & downregulated & FOS & EMT, migration and invasion & Li et al., 2020 \\
\hline & Placental tissues & downregulated & miR-206/IGF-1 & migration and invasion & Wu et al., 2020 \\
\hline & $\begin{array}{l}\text { Umbilical cord } \\
\text { tissues and MSCs }\end{array}$ & downregulated & VEGF/IDO & $\begin{array}{l}\text { proliferation, angiogenesis, } \\
\text { and Immunosuppressive }\end{array}$ & Li et al., 2017a \\
\hline MEG3 & Placental tissues & downregulated & $\begin{array}{l}\text { NF-kB, Caspase-3, and } \\
\text { Bax }\end{array}$ & apoptosis and migration & $\begin{array}{l}\text { Zhang et al., 2015; Liu W. et al., } \\
2017\end{array}$ \\
\hline MIR503HG & Placental tissues & upregulated & $\begin{array}{l}\text { NF-kB, MMP-2/-9, the } \\
\text { snail protein, and } \\
\text { E-cadherin }\end{array}$ & $\begin{array}{l}\text { proliferation, invasion, } \\
\text { migration, apoptosis and cell } \\
\text { cycle }\end{array}$ & Cheng et al., 2019a \\
\hline NR_002794 & Placental tissues & upregulated & - & $\begin{array}{l}\text { proliferation, invasion and } \\
\text { apoptosis }\end{array}$ & Ma et al., 2019 \\
\hline PGK1P2 & Placental tissues & downregulated & miR-330-5p & $\begin{array}{l}\text { angiogenesis, glycolysis } \\
\text { metabolism and } \\
\text { decidualization }\end{array}$ & Tong et al., 2018 \\
\hline PVT1 & Placental tissues & downregulated & PI3K/AKT pathway & $\begin{array}{l}\text { proliferation, migration and } \\
\text { invasion }\end{array}$ & $\begin{array}{l}\text { Xu Y. et al., 2018; Wang Q. et al., } \\
2019\end{array}$ \\
\hline RP11-465L10.10 & Placental tissues & downregulated & MMP-9 & invasion & Fan et al., 2016; Long et al., 2016 \\
\hline RPAIN & Placental tissues & upregulated & C1q & $\begin{array}{l}\text { proliferation, invasion and } \\
\text { apoptosis }\end{array}$ & Song et al., 2017 \\
\hline SNHG5 & Placental tissues & downregulated & miR-26a-5p/N-cadherin & $\begin{array}{l}\text { proliferation, migration and } \\
\text { invasion }\end{array}$ & Yang et al., 2019 \\
\hline SPRY4-IT1 & Placental tissues & upregulated & Wnt/ß-catenin pathway & $\begin{array}{l}\text { proliferation, migration and } \\
\text { apoptosis }\end{array}$ & Zou et al., 2013, Zuo et al., 2016 \\
\hline Storkhead box 2 & Placental tissues & upregulated & STOX2 & differentiation and invasion & Oudejans et al., 2016 \\
\hline TCL6 & Placental tissues & upregulated & PTEN & $\begin{array}{l}\text { cell proliferation and cell } \\
\text { cycle }\end{array}$ & Wu J.L. et al., 2019 \\
\hline TDRG1 & Placental tissues & downregulated & miR-214-5p, Notch & $\begin{array}{l}\text { proliferation, migration, and } \\
\text { invasion }\end{array}$ & Gong et al., 2020b \\
\hline TUG1 & Placental tissues & downregulated & $\begin{array}{l}\text { miR-204-5p, miR- } \\
\text { 29b/MCL1/NEGFA/MMP- } \\
2\end{array}$ & $\begin{array}{l}\text { migration, invasion, } \\
\text { proliferation, apoptosis and } \\
\text { angiogenesis }\end{array}$ & Yu et al., 2018; Li Q. et al., 2019 \\
\hline ZEB2-AS1 & Placental tissues & downregulated & miR-149/PGF & $\begin{array}{l}\text { proliferation, migration and } \\
\text { invasion }\end{array}$ & Gao et al., 2019 \\
\hline
\end{tabular}


likely maintains THSD7A mRNA expression through sponging of miR-210 (Tian et al., 2020).

The expression of lncRNA SPRY4-IT1 is elevated in PE placenta, which affects the EMT of vegetative cells via the $\mathrm{Wnt} / \beta$-catenin signaling pathway, thereby inhibiting trophoblast invasion and migration (Zuo et al., 2016). Similarly, lncRNA STOX2-IT3 regulates STOX2 gene expression to attenuate the differentiation and invasion of trophoblasts (Oudejans et al., 2016). Song et al. (2017) reported that IncRNA RPAIN is highly expressed in the placentas of patients with PE. When RPAIN is overexpressed, trophoblast proliferation and invasion is significantly inhibited, and trophoblast apoptosis increases significantly. Overexpression of RPAIN inhibits the expression of the complement protein C1q. C1q overexpression rescues the reduced cell invasion and enhanced apoptosis of trophoblast cells overexpressing RPAIN. Elevated RPAIN levels may play an important role in trophoblast invasion and spiral artery recasting via C1q regulation (Song et al., 2017).

\section{LncRNAs Inhibit Trophoblast Proliferation and Cell Cycle}

The colon cancer-related transcription factor 1 (CCAT1) gene is a lncRNA that is abnormally expressed in colon cancer tissues and is associated with proliferation activity and metastasis of colon cancer cells (Zhu et al., 2015). Higher expression of lncRNA CCAT1 was found in patients with PE. PE patients were divided into high-expression and low-expression groups according to CCAT1 expression. Compared with the lowexpression group, the systolic blood pressure, diastolic blood pressure, and urine protein levels of CCAT1 high-expression group were elevated, while birth weight was significantly higher in the low-expression group than the high-expression group. In addition, overexpression of CCAT1 to observe the function of CCAT1 in the proliferation activity and cell cycle of Bew and JEG-3 cells showed that interference with CCAT1 led to significant trophoblast proliferation and cell cycle acceleration, whereas overexpression of CCAT1 had the opposite results. After overexpression of CCAT1, the expression levels of E2F1, cyclin D, CDK2, and CDK4 in JEG3 cells were significantly reduced, while inhibition of CCAT1 led to significantly increased expression of E2F1, cyclin D, CDK2, and CDK4 in BeWo cells, suggesting that CCAT1 may be involved in the regulation of placental trophoblasts in $\mathrm{PE}$, and thus play a role in the pathogenesis of PE (Deng et al., 2015).

\section{LncRNAs Regulate Angiogenesis and Decidualization}

Impaired decidual function can lead to failure of trophoblast infiltration into blood vessels and insufficient placental function, thereby increasing the risk of PE. The expression level of lncRNA SPRY4-IT1 is 2.8 times higher in the placentas of PE patients than in normal pregnancy. Silencing of SPRY4-IT1 with small interfering RNA (siRNA) leads to an increase in its migration phenotype and a decrease in cell apoptosis. At the same time, siRNA silencing of SPRY4-IT1 results in decreased tube formation ability, while overexpression of SPRY4-IT1 enhances tube formation (Zou et al., 2013). Knockout of SPRY14-IT1 leads to decreased gene and protein expression levels of E-cadherin and $\beta$-catenin, as well as increased vimentin expression. The mechanism of those effects may be the binding of SPRY14-IT1 to the cytoplasmic RNA-binding protein $\mathrm{HuR}$, and the resulting complex directly binding to $\beta$-catenin mRNA (Zuo et al., 2016). The interaction between HuR and $\beta$-catenin proteins leads to an imbalance in $\beta$-catenin mRNA expression, which has been verified in other cell types (Chou et al., 2015). Knockdown of SPRY14-IT1 can lead to down-regulation of Wnt3 and Wnt5B, the downstream targets of $\beta$-catenin. Strict regulation of Wnt/ $\beta$-catenin signaling plays important roles in maintaining the phenotype of epithelial cells and the development of cell-cell connections. The loss of this pathway leads to type 1 EMT. The EMT of extravillous trophoblasts is a key step in the invasion of maternal decidua tissue, and is essential to uterine spiral artery recasting and successful pregnancy (Gude et al., 2004). Expression of SPRY4-IT1 is associated with the formation of an endothelial cell-like tubular network, which is an important process in angiogenesis; in particular, high expression of SPRY4IT1 in the placenta of patients with PE may be related to the process of uterine spiral artery recasting.

Phosphoglycerate kinase 1 (PGK1) is an enzyme involved in the glycolytic pathway, which is the main metabolic process undertaken by DCs. The sequences of lncRNA PGK1P2 and PGK1 are similar. Normal decidualization is essential for normal pregnancy. In one study, PGK1 and PGK1P2 mRNA expression and PGK1 protein level were lower in decidua of severe PE than in the normal pregnancy control group. Further research showed that PGK1 and PGK1P2 are a pair of ceRNAs targeting miR$330-5$ p. They play a crucial role in human decidualization by regulating angiogenesis and glycolytic metabolism. Lack of PGK1 and PGK1P2 in the decidua inhibits the decidualization process and may subsequently lead to PE (Tong et al., 2018).

\section{LncRNAs Participate in Inflammation and Immune Regulation}

LncRNA MALAT1 is also involved in immune regulation and inflammation. MALAT1 reduces the secretion of inflammatory factors TNF- $\alpha$ and IL- 6 , and inhibits the expression of TGF- $\beta$ and NF- $\kappa$ B in trophoblastic cells (Zhang Y. et al., 2020). lncRNA H19 plays role in inflammatory diseases (Wang W.T. et al., 2016). Excessive inflammation of maternal endothelial cells is a characteristic of PE (Chen et al., 2016). The placental tissues of PE patients have higher levels of lncRNA H19 than healthy controls. Overexpression of lncRNA H19 activates PI3K. The $\mathrm{PI} 3 \mathrm{~K} / \mathrm{AKT} / \mathrm{mTOR}$ pathway reduces cell viability and promotes autophagy in trophoblasts, but increases cell invasion (Xu J. et al., 2018). lncRNA DC is expressed exclusively in human DCs and induces DC differentiation and maturation by promoting the phosphorylation of STAT3 (Wang P. et al., 2014). lnc-DC and p-TAT3 increase in PE, and overexpression of lnc-DC inhibits trophoblast invasion, increases p-STAT3 levels, and increases the ratios of tissue inhibitor of metalloproteinase (TIMP)-1 to MMP9 and TIMP-2 to MMP-2 (Zhang W. et al., 2020). In addition, overexpression of lnc-DC can cause excessive maturation of DCs in patients with PE and increase the abundance of Th1 cells, indicating that lncRNA DC has immunomodulatory activity (Zhang W. et al., 2017). 


\section{CircRNAs IN PE}

\section{CircRNA}

Circular RNA is a closed circRNA with no $5^{\prime}$ cap and with a $3^{\prime}$ poly-A tail (Memczak et al., 2013). The sequence of circRNA is highly conserved, and its circular structure resists degradation by exonucleases. Its structure is relatively stable and highly expressed, and it plays roles in gene transcription and posttranscriptional regulation (Memczak et al., 2013). The length of circRNAs is in the range of 200-2,000 bp, and most are about 500 bp. circRNA is a type of endogenous RNA that is transcribed by RNA polymerase II (Zhang et al., 2018), and can be divided into non-coding and coding circRNAs. Coding circRNA has an open reading frame that generally contains at least one internal ribosome entry site (Li et al., 2019c). The closed-loop structure can be formed through the reverse splicing mechanism, wherein the upstream $5^{\prime}$ splice site and downstream $3^{\prime}$ splice site are connected by linear mRNA; therefore, canonical spliceosome signaling may be involved in the regulation of circRNA biogenesis (Chen, 2016). circRNA expression is tissue-specific, and diverse types of circRNA are expressed (Xia et al., 2017). According to the source of splicing, circRNA can be divided into exon source, intron source, or exon and intron source types (Han et al., 2018). Most circRNAs are derived from exons, and a small number are formed through direct circularization of introns. The main biological functions of circRNA are as follows. As a miRNA sponge, circRNA is rich in miRNA-binding sites and can function as ceRNA. circRNA can absorb miRNA through sponging or base complementation and inhibit its binding to mRNA, increasing mRNA expression (Han et al., 2018). By participating in the regulation of linear splicing (Hansen et al., 2013), it functions alongside RNA polymerase II as a cisacting element and regulatory gene in transcription (Zhang $\mathrm{Y}$. et al., 2013). Moreover, circRNA can interact with RNA-binding proteins as a scaffold to promote, align, and regulate RNA functions (Memczak et al., 2013) play roles in transcription and translation (Pamudurti et al., 2017), and act as an m6A recognition protein, known as YTH N6-methyladenosine RNA binding protein 3 (YTHDF3). It can bind to the modified start site of circRNA and recruit translation initiation factors such as eIF4G2 for translation (Yang et al., 2017).

\section{CircRNAs in the Pathogenesis of PE}

As a novel type of ncRNA, circRNA has notable advantages for development and application as a clinical biomarker. Although few studies on circRNA in the pathogenesis of PE have been conducted, it has been revealed that circRNA in the plasma and placenta tissue of patients with PE can block the inhibitory effect of miRNA on its target mRNA by binding to miRNA, thereby regulating $\mathrm{mRNA}$ expression. This mechanism may allow circRNA to participate in the pathogenesis of PE.

Deng et al. (2019) integrated RNA sequencing data from human placentas with severe $\mathrm{PE}$ and normal pregnancies, and found that 180 circRNAs were differentially expressed in placentas with severe $\mathrm{PE}$, including 94 up-regulated and 86 down-regulated circRNAs. Most of the detected circRNAs have not been annotated. Bioinformatics analysis of differentially expressed circRNAs shows that most are involved in vasodilation, blood vessel size regulation, protein transport and localization, and cancer pathways. circRNA mainly acts in a regulatory role as a sponge of miRNA. ceRNA inhibits its binding to mRNA and increases mRNA expression. The circ_0085296 level was elevated in PE placental tissue, while miR-144 was down-regulated (Zhu et al., 2020). Up-regulation of circ_0085296 inhibits trophoblast proliferation, invasion, and migration. miR-144 directly binds to circ_0085296 and E-cadherin, and circ_0085296 acts as a sponge of miR-144 to regulate the expression of E-cadherin. Moreover, miR-144 inhibition and E-cadherin overexpression weaken the effect of circ_0085296 on cellular processes in trophoblast cells. hsa_circ_011277 (Ou et al., 2020), hsa_circ_0011460 (Deng et al., 2019), and hsa_circ_0006772 (Shen et al., 2019) are significantly elevated in the placenta of PE patients. circ_011277 reduces the inhibitory effect of $\mathrm{miR}-494-3 \mathrm{p}$ by regulating the expression of HtrA serine peptidase 1 (HTRA1) and Notch1 (Ou et al., 2020), while hsa_circ_0011460 directly targets the solute carrier organic anion transporter family member (PGT) interaction (Deng et al., 2019). hsa_circ_0006772 has a negative regulatory effect on trophoblast migration and EMT. Meanwhile, the hsa_circ_0006772 sponge miR-762 inhibits the activity of miR-762 and increases the protein level of the EMTrelated transcription factor grainyhead like transcription factor 2 (Grhl2) (Shen et al., 2019). hsa_circ_0000284 (Zhang Y. et al., 2019) and hsa_circ_0003286 (Zhou et al., 2018) were reduced in $\mathrm{PE}$ placental tissue. After siRNA transfection to silence hsa_circ_0000284, the migration, invasion, proliferation, and tube formation activities of HTR8/SVneo cells were inhibited, while siRNA transfection silencing hsa_circ_0003286 significantly reduced cell invasion.

Expression of hsa_circ_0036877 in the placenta was lower in pregnant women with $\mathrm{PE}$ than in normal pregnant women, but that in peripheral blood was higher in pregnant women with PE than in normal pregnant women (Hu et al., 2019). hsa_circ_0036877 combines miR-519d-3p and miR-15b-5p, and may act as a miRNA sponge in the pathogenesis of $\mathrm{PE}(\mathrm{Hu}$ et al., 2018). Syncytial trophoblast cell necrosis is a direct result of unbalanced regulation of apoptosis, and leads to increased release of trophoblast granules into the circulating blood of patients with PE (Huppertz et al., 2006). hsa_circ_0036877 may be an extracellular nucleic acid derived from the placenta. The marked increase in apoptosis of syncytial trophoblast cells may explain the low expression of hsa_circ_0036877 in the PE placenta but high expression in circulating blood.

Liu et al., 2019 analyzed differentially expressed circRNA, lncRNA, miRNA, and mRNA based on RNA sequencing data from placenta tissues and data in the Gene Expression Omnibus (GEO) database using gene set enrichment analysis and other bio-informatics methods. The results showed that the JAK/STAT signaling pathway was activated and miR-100-5p was down-regulated in both PE sequencing data and GEO data, and the expression levels of lncRNA-1492, hsa_circ_0088196, and leukemia inhibitory factor (LIF), which have targeted regulatory relationships with miR-100-5p, were up-regulated. A luciferase reporter experiment demonstrated the presence of 
a ceRNA regulatory network in PE, wherein lncRNA-1492 and hsa_circ_0088196 target the inhibitory effect of miR-100-5p on LIF, and up-regulated LIF activates the JAK/STAT pathway, promoting the development of PE.

During early pregnancy before the onset of $\mathrm{PE}$, prediction, effective intervention, prevention, and control of the disease are of great significance (Lavallee, 2015). circRNA has characteristics of stability, universality, specificity, and conservation, making it a more suitable biomarker than other RNA types (Lasda and Parker, 2014). A prospective study of circRNA expression in the blood cells of PE patients before 20 weeks of pregnancy and healthy pregnant women showed that PE patients had significantly higher hsa_circ_101222 (Zhang Y.G. et al., 2016). Analysis using bioinformatics prediction (Liu et al., 2019) indicated that hsa_circ_101222 may interact with miR-181, which is closely related to the pathogenesis of PE (Liu et al., 2012), while the miRNA response elements of hsa_circ_0001855 and hsa_circ_0004904 were identified as miR-138-5p, miR-30c-1-3p, miR-623, miR-30c-2-3p, miR-134-3p, miR-29a-5p, and miR-765, all of which target pregnancy-associated plasma protein A (PAPPA), and miR-29a-5p, and are closely related to the pathogenesis of PE (Stubert et al., 2014). The area under the receiver operating characteristic curve for the two circRNAs combined with PAPP-A can reach 0.940 (95\% confidence interval: 0.8691.000), suggesting that hsa_circ_0004904 and hsa_circ_0001855 in combination with PAPP-A are promising biomarkers for the prediction of PE.

\section{CONCLUSION}

Preeclampsia is asymptomatic in the early stage, so early diagnosis is essential for PE. To identify potential biomarkers of PE, many groups focused on non-coding RNAs in maternal plasma and serum. As regards miRNAs and lncRNAs in maternal blood, there are still no sufficient data to understand if they can be used as promising markers for PE monitoring and screening, since almost all of the case-control designs only considered the affected cases and the unaffected cases. Besides, the population recruited by $\mathrm{PE}$ is heterogeneous, including variation in the definition of PE and the timing of screening during pregnancy, so the possible independent positive predictive value of miRNAs and IncRNAs is unclear. Additionally, abnormal expression of miRNAs and lncRNAs is only found in symptomatic PE cases. Because the true incidence is not provided, miRNAs and lncRNAs are currently useless for the possible implementation of screening purposes. Considering the molecular advantages of circRNAs, studies on circRNA are more focused on possible use for screening purposes, and are generally better designed, as they consider a wider number of cases. The first study to report circRNA analysis in pregnant women with PE before the onset of symptoms found that hsa_circ_0004904 and hsa_circ_0001855 were significantly elevated in pregnant women with PE compared with healthy pregnant women. The area under the curve of the combined model was 0.94 in the predicted PE subject (Jiang et al., 2018). Unfortunately, even though some papers reported the possible screening performance of circRNAs at the first or second trimester of pregnancy, circRNAs have not been used successfully for any screening program for PE considering the small cohort of patients studied. Further prospective studies with larger samples from different gestational stages are needed to understand the possible role of circRNAs in predicting and monitoring PE. The abnormal expression of PLGF, PAPP-A, PP13, and sFlt1 in the pathological process of $\mathrm{PE}$ has potential value in the prediction of $\mathrm{PE}$. In addition to the above factors, there are more biological indicators in the clinical application value of PE that have been found. Considering the economy and efficiency of clinical application, multi-index combined prediction, including PAPP-A, PP13, sFlt-1, circRNAs, and other biological indicators, combined with maternal history, ultrasound, and so on, may have a greater application prospect.

The pathogenesis of early- and late-onset PE is different, and the role of non-coding RNAs in them may also be different. Deep sequencing compared the expression profiles of tissue and circulating miRNAs in pregnant women with early- and late-onset $\mathrm{PE}$, and found differential expression of miRNA in the two groups of tissues (Timofeeva et al., 2018). In earlyonset PE, miR-431, miR-518a-5p, and miR-124 were up-regulated in the placenta tissues (Lykoudi et al., 2018), and miR-423$5 \mathrm{p}$ was up-regulated in the circulating blood (Timofeeva et al., 2018), whereas miR-544 and miR-3942 were down-regulated in the placenta tissues (Lykoudi et al., 2018). In late-onset PE, miR-383 and miR-1183 were up-regulated in the placenta tissues (Lykoudi et al., 2018), whereas miR-23b-5p and miR99b-5p were down-regulated in the circulating blood (Mavreli et al., 2020). However, the functional significance of these miRNAs in the pathogenesis of PE has not been confirmed and elucidated. Although great efforts have been made to explore the pathogenesis of miRNA in PE, most of the samples obtained are from patients with early-onset $\mathrm{PE}$, and few studies have been devoted to comparing the pathogenesis of miRNA in earlyand late-onset PE. Further exploration and clarification of the similarities and differences of non-coding RNA involved in the pathology of early- and late-onset PE can provide new ideas for explaining the pathogenesis of PE.

In summary, from the proliferation, invasion, and migration of trophoblast cells to cell cycle progression, changes in the abovedescribed ncRNA expression above may affect the functions of those cells and eventually lead to PE. The discovery of early diagnostic markers is key to early pregnancy intervention. With the development of sequencing technologies, methods for detecting differentially expressed ncRNAs in the placenta and plasma of PE patients have been rapidly established. As research into the expression and function of ncRNA remains in its infancy, exploring the reasons underlying the differences between earlyand late-onset PE, the discovery of additional PE-related or PEspecific ncRNAs, and corresponding target gene investigations will be major directions of future research. These studies will help clarify the pathological mechanism of $\mathrm{PE}$ and provide a new target for its early prevention.

\section{AUTHOR CONTRIBUTIONS}

All authors contributed to the writing and editing of the manuscript and approved the submitted version. 


\section{FUNDING}

This work was supported by the National Natural Science Foundation of China (81671473), the Post doctorate Foundation of China (2019M651963), the Post doctorate Foundation of

\section{REFERENCES}

Ali, L. E., Salih, M. M., Elhassan, E. M., Mohmmed, A. A., and Adam, I. (2019). Placental growth factor, vascular endothelial growth factor, and hypoxia-inducible factor-1alpha in the placentas of women with pre-eclampsia. J. Matern. Fetal. Neonatal. Med. 32, 2628-2632. doi: 10.1080/14767058.2018. 1443066

Anton, L., Olarerin-George, A. O., Hogenesch, J. B., and Elovitz, M. A. (2015). Placental expression of miR-517a/b and miR-517c contributes to trophoblast dysfunction and preeclampsia. PLoS One 10:e122707. doi: 10.1371/journal. pone.0122707

Berkane, N., Lefevre, G., and Hertig, A. (2007). Angiogenic factors in preeclampsia: so complex, so simple? Nephrol. Dial. Trans. 22, 2753-2756. doi: 10.1093/ndt/ gfm 429

Brkic, J., Dunk, C., O’Brien, J., Fu, G., Nadeem, L., Wang, Y. L., et al. (2018). MicroRNA-218-5p promotes endovascular trophoblast differentiation and spiral artery remodeling. Mol. Ther. 26, 2189-2205. doi: 10.1016/j.ymthe.2018. 07.009

Bugge, M., Bergstrom, B., Eide, O. K., Solli, H., Kjonstad, I. F., Stenvik, J., et al. (2017). Surface toll-like receptor 3 expression in metastatic intestinal epithelial cells induces inflammatory cytokine production and promotes invasiveness. J. Biol. Chem. 292, 15408-15425. doi: 10.1074/jbc.M117.784090

Burton, G. J., Redman, C. W., Roberts, J. M., and Moffett, A. (2019). Pre-eclampsia: pathophysiology and clinical implications. BMJ 366:12381. doi: 10.1136/bmj. 12381

Cao, C., Li, J., Li, J., Liu, L., Cheng, X., and Jia, R. (2017). Long non-coding RNA Uc.187 Is upregulated in preeclampsia and modulates proliferation. Apoptosis, and Invasion of HTR-8/SVneo Trophoblast Cells. J. Cell Biochem. 118, 14621470. doi: $10.1002 /$ jcb. 25805

Chatterjee, P., Weaver, L. E., Doersch, K. M., Kopriva, S. E., Chiasson, V. L., Allen, S. J., et al. (2012). Placental toll-like receptor 3 and toll-like receptor 7/8 activation contributesto preeclampsia in humans and mice. PLoS One 7:e41884. doi: 10.1371/journal.pone.0041884

Chen, F. R., Zheng, L. M., Wu, D. C., Gong, H. M., Cen, H., and Chen, W. C. (2020). [Regulatory relationship between IncRNA KCNQ1OT1 and miR-146a3p in preeclampsia]. Zhonghua Fu Chan Ke Za Zhi 55, 535-543. doi: 10.3760/ cma.j.cn112141-20200322-00246

Chen, H., Meng, T., Liu, X., Sun, M., Tong, C., Liu, J., et al. (2015). Long non-coding RNA MALAT-1 is downregulated in preeclampsia and regulates proliferation, apoptosis, migration and invasion of JEG-3 trophoblast cells. Int. J. Clin. Exp. Pathol. 8, 12718-12727.

Chen, J., and Khalil, R. A. (2017). Matrix metalloproteinases in normal pregnancy and preeclampsia. Prog. Mol. Biol. Transl. Sci. 148, 87-165. doi: 10.1016/bs. pmbts.2017.04.001

Chen, L. L. (2016). The biogenesis and emerging roles of circular RNAs. Nat. Rev. Mol. Cell. Biol. 17, 205-211. doi: 10.1038/nrm.2015.32

Chen, Q., Sousa, J. D., Snowise, S., Chamley, L., and Stone, P. (2016). Reduction in the severity of early onset severe preeclampsia during gestation may be associated with changes in endothelial cell activation: a pathological case report. Hypertens Pregnancy 35, 32-41. doi: 10.3109/10641955.2015.1100309

Chen, S., Zhao, G., Miao, H., Tang, R., Song, Y., Hu, Y., et al. (2015). MicroRNA494 inhibits the growth and angiogenesis-regulating potential of mesenchymal stem cells. Febs Lett 589, 710-717. doi: 10.1016/j.febslet.2015.01.038

Chen, Y., Ding, H., Wei, M., Zha, W., Guan, S., Liu, N., et al. (2020). MSCSecreted exosomal H19 promotes trophoblast cell invasion and migration by downregulating let-7b and upregulating FOXO1. Mol. Ther. Nucleic Acids 19, 1237-1249. doi: 10.1016/j.omtn.2019.11.031

Cheng, D., Jiang, S., Chen, J., Li, J., Ao, L., and Zhang, Y. (2019b). Upregulated long noncoding RNA Linc00261 in pre-eclampsia and its effect on trophoblast
Jiangsu Province (2018Z093), Jiangsu Provincial Medical Youth Talent of the Project of Invigorating Health Care through Science, Technology and Education (QNRC2016165), and the Foundation of top notch young and middle-aged medical and health talents in Wuxi (BJ2020079).

invasion and migration via regulating miR-558/TIMP4 signaling pathway. J. Cell Biochem. 120, 13243-13253. doi: 10.1002/jcb.28598

Cheng, D., Jiang, S., Chen, J., Li, J., Ao, L., and Zhang, Y. (2019a). The increased lncRNA MIR503HG in preeclampsia modulated trophoblast cell proliferation, invasion, and migration via regulating matrix metalloproteinases and NFkappaB signaling. Dis. Mark. 2019:4976845. doi: 10.1155/2019/4976845

Chim, S. S., Shing, T. K., Hung, E. C., Leung, T. Y., Lau, T. K., Chiu, R. W., et al. (2008). Detection and characterization of placental microRNAs in maternal plasma. Clin. Chem. 54, 482-490. doi: 10.1373/clinchem.2007.097972

Chou, S. D., Murshid, A., Eguchi, T., Gong, J., and Calderwood, S. K. (2015). HSF1 regulation of beta-catenin in mammary cancer cells through control of HuR/elavL1 expression. Oncogene 34, 2178-2188. doi: 10.1038/onc.2014.177

Delas, M. J., and Hannon, G. J. (2017). IncRNAs in development and disease: from functions to mechanisms. Open Biol. 7:170121. doi: 10.1098/rsob.170121

Deng, L., Yang, S. B., Xu, F. F., and Zhang, J. H. (2015). Long noncoding RNA CCAT1 promotes hepatocellular carcinoma progression by functioning as let-7 sponge. J. Exp. Clin. Cancer Res. 34:18. doi: 10.1186/s13046-015-0136-7

Deng, N., Lei, D., Huang, J., Yang, Z., Fan, C., and Wang, S. (2019). Circular RNA expression profiling identifies hsa_circ_0011460 as a novel molecule in severe preeclampsia. Pregnancy Hypertens 17, 216-225. doi: 10.1016/j.preghy.2019.06. 009

Ding, G. C., Chen, M., Wang, Y. X., Rui, C., Xu, W., Ding, H. J., et al. (2016). MicroRNA-128a-induced apoptosis in HTR-8/SVneo trophoblast cells contributes to pre-eclampsia. Biomed. Pharmacother. 81, 63-70. doi: 10.1016/j. biopha.2016.03.040

Djuranovic, S., Nahvi, A., and Green, R. (2011). A parsimonious model for gene regulation by miRNAs. Science 331, 550-553. doi: 10.1126/science.1191138

Dong, D., Khoong, Y., Ko, Y., and Zhang, Y. (2020). microRNA-646 inhibits angiogenesis of endothelial progenitor cells in pre-eclamptic pregnancy by targeting the VEGF-A/HIF-1alpha axis. Exp. Ther. Med. 20, 1879-1888. doi: 10.3892/etm.2020.8929

Dong, X., Zhang, Y., Chen, X., and Xue, M. (2020). Long noncoding RNA LINC00511 regulates the proliferation, apoptosis, invasion and autophagy of trophoblast cells to mediate pre-eclampsia progression through modulating the miR-31-5p/homeobox protein A7 axis. J. Obstet. Gynaecol. Res. 46, 1298-1309. doi: $10.1111 /$ jog. 14344

Duhig, K., Vandermolen, B., and Shennan, A. (2018). Recent advances in the diagnosis and management of pre-eclampsia. F1000 Res. 7:242. doi: 10.12688/ f1000research.12249.1

Eghbal-Fard, S., Yousefi, M., Heydarlou, H., Ahmadi, M., Taghavi, S., Movasaghpour, A., et al. (2019). The imbalance of Th17/Treg axis involved in the pathogenesis of preeclampsia. J. Cell. Physiol. 234, 5106-5116. doi: $10.1002 /$ jcp. 27315

Faas, M. M., and De Vos, P. (2018). Innate immune cells in the placental bed in healthy pregnancy and preeclampsia. Placenta 69, 125-133. doi: 10.1016/j. placenta.2018.04.012

Fan, M., Xu, Y., Hong, F., Gao, X., Xin, G., Hong, H., et al. (2016). Rac1/betacatenin signalling pathway contributes to trophoblast cell invasion bytargeting snail and MMP9. Cell Physiol. Biochem. 38, 1319-1332. doi: 10.1159/000443076

Fang, M., Du, H., Han, B., Xia, G., Shi, X., Zhang, F., et al. (2017). Hypoxia-inducible microRNA-218 inhibits trophoblast invasion by targeting LASP1:Implications for preeclampsia development. Int. J. Biochem. Cell. Biol. 87, 95-103. doi: 10.1016/j.biocel.2017.04.005

Fu, G., Ye, G., Nadeem, L., Ji, L., Manchanda, T., Wang, Y., et al. (2013). MicroRNA-376c impairs transforming growth factor-beta and nodal signaling to promote trophoblast cell proliferation and invasion. Hypertension 61, 864872. doi: 10.1161/HYPERTENSIONAHA.111.203489

Fu, J. Y., Xiao, Y. P., Ren, C. L., Guo, Y. W., Qu, D. H., Zhang, J. H., et al. (2018). Up-regulation of miR-517-5p inhibits ERK/MMP-2 pathway: potential role in 
preeclampsia. Eur. Rev. Med. Pharmacol. Sci. 22, 6599-6608. doi: 10.26355/ eurrev_201810_16134

Gan, L., Liu, Z., Wei, M., Chen, Y., Yang, X., Chen, L., et al. (2017). MiR-210 and miR-155 as potential diagnostic markers for pre-eclampsia pregnancies. Medicine (Baltimore) 96:e7515. doi: 10.1097/MD.000000000000 7515

Gao, Y., Guo, X., Li, Y., Sha, W., and She, R. (2019). The decreased lncRNA ZEB2-AS1 in pre-eclampsia controls the trophoblastic cell line HTR-8/SVneo's invasive and migratory abilities via the miR-149/PGF axis. J. Cell. Biochem. 120, 17677-17686. doi: 10.1002/jcb.29034

Gao, Y., She, R., Wang, Q., Li, Y., and Zhang, H. (2018). Up-regulation of miR-299 suppressed the invasion and migration of HTR-8/SVneo trophoblast cells partly via targeting HDAC2 in pre-eclampsia. Biomed. Pharmacother. 97, 1222-1228. doi: 10.1016/j.biopha.2017.11.053

Geldenhuys, J., Rossouw, T. M., Lombaard, H. A., Ehlers, M. M., and Kock, M. M. (2018). Disruption in the regulation of immune responses in the placental subtype of preeclampsia. Front. Immunol. 9:1659. doi: 10.3389/fimmu.2018. 01659

Gomes, A. Q., Nolasco, S., and Soares, H. (2013). Non-coding RNAs: multitasking molecules in the cell. Int. J. Mol. Sci. 14, 16010-16039. doi: 10.3390/ ijms 140816010

Gong, F., Chai, W., Wang, J., Cheng, H., Shi, Y., Cui, L., et al. (2020a). miR-214$5 \mathrm{p}$ suppresses the proliferation, migration and invasion of trophoblast cells in pre-eclampsia by targeting jagged 1 to inhibit notch signaling pathway. Acta Histochem 122:151527. doi: 10.1016/j.acthis.2020.151527

Gong, F., Cheng, H., Shi, Y., Cui, L., and Jia, G. (2020b). LncRNA TDRG1/miR214-5p axis affects preeclampsia by modulating trophoblast cells. Cell. Biochem. Funct. 38, 352-361. doi: 10.1002/cbf.3480

Gude, N. M., Roberts, C. T., Kalionis, B., and King, R. G. (2004). Growth and function of the normal human placenta. Thromb. Res. 114, 397-407. doi: 10. 1016/j.thromres.2004.06.038

Guo, L., Zhao, Y., Yang, S., Zhang, H., and Chen, F. (2014). An integrated analysis of miRNA, IncRNA, and mRNA expression profiles. Biomed. Res. Int. 2014:345605. doi: 10.1155/2014/345605

Gusar, V., Timofeeva, A., Chagovets, V., Kan, N., Vasilchenko, O., Prozorovskaya, K., et al. (2020). Preeclampsia: the interplay between oxygen-sensitive miRNAs and erythropoietin. J. Clin. Med. 9:574. doi: 10.3390/jcm9020574

Guttman, M., and Rinn, J. L. (2012). Modular regulatory principles of large non-coding RNAs. Nature 482, 339-346. doi: 10.1038/nature10887

Han, B., Chao, J., and Yao, H. (2018). Circular RNA and its mechanisms in disease: From the bench to the clinic. Pharmacol. Ther. 187, 31-44. doi: 10.1016/j. pharmthera.2018.01.010

Han, X., Niu, C., Zuo, Z., Wang, Y., Yao, L., and Sun, L. (2020). MiR-342-3p inhibition promotes cell proliferation and invasion by directly targeting ID4 in pre-eclampsia. J. Obstet. Gynaecol. Res. 46, 49-57. doi: 10.1111/jog.14150

Hansen, T. B., Jensen, T. I., Clausen, B. H., Bramsen, J. B., Finsen, B., Damgaard, C. K., et al. (2013). Natural RNA circles function as efficient microRNA sponges. Nature 495, 384-388. doi: 10.1038/nature11993

Hong, F., Li, Y., and Xu, Y. (2014). Decreased placental miR-126 expression and vascular endothelial growth factor levels in patients with pre-eclampsia. J. Int. Med. Res. 42, 1243-1251. doi: 10.1177/0300060514540627

Hromadnikova, I., Dvorakova, L., Kotlabova, K., and Krofta, L. (2019). The prediction of gestational hypertension, preeclampsia and fetal growth restriction via the first trimester screening of plasma exosomal C19MC microRNAs. Int. J. Mol. Sci. 20:2972. doi: 10.3390/ijms20122972

Hromadnikova, I., Kotlabova, K., Ivankova, K., Vedmetskaya, Y., and Krofta, L. (2017). Profiling of cardiovascular and cerebrovascular disease associated microRNA expression in umbilical cord blood in gestational hypertension, preeclampsia andfetal growth restriction. Int. J. Cardiol. 249, 402-409. doi: 10.1016/j.ijcard.2017.07.045

Hromadnikova, I., Kotlabova, K., Ondrackova, M., Kestlerova, A., Novotna, V., Hympanova, L., et al. (2013). Circulating C19MC microRNAs in preeclampsia, gestational hypertension, and fetalgrowth restriction. Med. Inf. 2013:186041. doi: 10.1155/2013/186041

Hu, X., Ao, J., Li, X., Zhang, H., Wu, J., and Cheng, W. (2018). Competing endogenous RNA expression profiling in pre-eclampsia identifies hsa_circ_0036877 as a potential novel blood biomarker for early pre-eclampsia. Clin. Epigenetics 10:48. doi: 10.1186/s13148-018-0482-3
Hu, X., Li, X., Tian, G. G., Zhang, H., Cheng, W., and Wu, J. (2019). Expression profiling dataset of competing endogenous RNA in pre-eclampsia. Data Brief. 27:104795. doi: 10.1016/j.dib.2019.104795

Huang, X., Wu, L., Zhang, G., Tang, R., and Zhou, X. (2019). Elevated microrna181a-5p contributes to trophoblast dysfunction and preeclampsia. Reprod. Sci. 26, 1121-1129. doi: 10.1177/1933719118808916

Huppertz, B., Kadyrov, M., and Kingdom, J. C. (2006). Apoptosis and its role in the trophoblast. Am. J. Obstet. Gynecol. 195, 29-39. doi: 10.1016/j.ajog.2005.07.039

Ishibashi, O., Ohkuchi, A., Ali, M. M., Kurashina, R., Luo, S. S., Ishikawa, T., et al. (2012). Hydroxysteroid (17-beta) dehydrogenase 1 is dysregulated by miR-210 and miR-518cthat are aberrantly expressed in preeclamptic placentas: a novel marker for predicting preeclampsia. Hypertension 59, 265-273. doi: 10.1161/ HYPERTENSIONAHA.111.180232

Ji, L., Zhang, L., Li, Y., Guo, L., Cao, N., Bai, Z., et al. (2017). MiR-136 contributes to pre-eclampsia through its effects on apoptosis and angiogenesis of mesenchymal stem cells. Placenta 50, 102-109. doi: 10.1016/j.placenta.2017. 01.102

Ji, P., Diederichs, S., Wang, W., Boing, S., Metzger, R., Schneider, P. M., et al. (2003). MALAT-1, a novel noncoding RNA, and thymosin beta4 predict metastasis and survival in early-stage non-small cell lung cancer. Oncogene 22, 8031-8041. doi: 10.1038/sj.onc. 1206928

Jiang, F., Li, J., Wu, G., Miao, Z., Lu, L., Ren, G., et al. (2015). Upregulation of microRNA335 and microRNA584 contributes to the pathogenesis of severe preeclampsia through downregulation of endothelial nitric oxide synthase. Mol. Med. Rep. 12, 5383-5390. doi: 10.3892/mmr.2015.4018

Jiang, L., Long, A., Tan, L., Hong, M., Wu, J., Cai, L., et al. (2017). Elevated microRNA-520g in pre-eclampsia inhibits migration and invasion of trophoblasts. Placenta 51, 70-75. doi: 10.1016/j.placenta.2017.02.001

Jiang, M., Lash, G. E., Zhao, X., Long, Y., Guo, C., and Yang, H. (2018). CircRNA-0004904, CircRNA-0001855, and papp-a: potential novel biomarkers for theprediction of preeclampsia. Cell Physiol. Biochem. 46, 2576-2586. doi: $10.1159 / 000489685$

Jin, M., Li, H., Xu, H., Huo, G., and Yao, Y. (2017). MicroRNA-20b inhibits trophoblast cell migration and invasion by targeting MMP-2. Int. J. Clin. Exp. Pathol. 10, 10901-10909.

Kim, J., Lee, K. S., Kim, J. H., Lee, D. K., Park, M., Choi, S., et al. (2017). Aspirin prevents TNF-alpha-induced endothelial cell dysfunction by regulating the NFkappaB-dependent miR-155/eNOS pathway: role of a miR-155/eNOS axis in preeclampsia. Free Radic Biol. Med. 104, 185-198. doi: 10.1016/j.freeradbiomed. 2017.01.010

Kopriva, S. E., Chiasson, V. L., Mitchell, B. M., and Chatterjee, P. (2013). TLR3induced placental miR-210 down-regulates the STAT6/interleukin-4 pathway. PLoS One 8:e67760. doi: 10.1371/journal.pone.0067760

Lasda, E., and Parker, R. (2014). Circular RNAs: diversity of form and function. RNA 20, 1829-1842. doi: 10.1261/rna.047126.114

Lavallee, L. (2015). Clinical presentation, assessment and management of preeclampsia. Nurs. Stand. 29, 51-59. doi: 10.7748/ns.29.45.51.e9952

Li, J., Wang, J. M., Liu, Y. H., Zhang, Z., Han, N., Wang, J. Y., et al. (2017c). [Effect of microRNA-106b on the invasion and proliferation of trophoblasts through targeting MMP-2]. Zhonghua Fu Chan Ke Za Zhi 52, 327-332. doi: 10.3760/cma.j.issn.0529-567X.2017.05.007

Li, J., Wu, G., Cao, Y., and Hou, Z. (2019). Roles of miR-210 in the pathogenesis of pre-eclampsia. Arch. Med. Sci. 15, 183-190. doi: 10.5114/aoms.2018.73129

Li, L., Zhang, X., Hong, S. L., Chen, Y., and Ren, G. H. (2018). Long noncoding HOTTIP regulates preeclampsia by inhibiting RND3. Eur. Rev. Med. Pharmacol. Sci. 22, 3277-3285. doi: 10.26355/eurrev_201806_15146

Li, P., Guo, W., Du, L., Zhao, J., Wang, Y., Liu, L., et al. (2013). microRNA-29b contributes to pre-eclampsia through its effects on apoptosis, invasion and angiogenesis of trophoblast cells. Clin. Sci. (Lond) 124, 27-40. doi: 10.1042/ CS20120121

Li, Q., Wang, T., Huang, S., Zuo, Q., Jiang, Z., Yang, N., et al. (2020). LncRNA MALAT1 affects the migration and invasion of trophoblast cells by regulating FOS expression in early-onset preeclampsia. Pregnancy Hypertens 21, 50-57. doi: 10.1016/j.preghy.2020.05.001

Li, Q., Zhang, J., Su, D. M., Guan, L. N., Mu, W. H., Yu, M., et al. (2019). lncRNA TUG1 modulates proliferation, apoptosis, invasion, and angiogenesis via targeting miR-29b in trophoblast cells. Hum. Geno. 13:50. doi: 10.1186/ s40246-019-0237-z 
Li, X., Li, C., Dong, X., and Gou, W. (2014). MicroRNA-155 inhibits migration of trophoblast cells and contributes to the pathogenesis of severe preeclampsia by regulating endothelial nitric oxide synthase. Mol. Med. Rep. 10, 550-554. doi: 10.3892/mmr.2014.2214

Li, X., Song, Y., Liu, D., Zhao, J., Xu, J., Ren, J., et al. (2017b). MiR-495 Promotes senescence of mesenchymal stem cells by targeting bmi-1. Cell. Physiol. Biochem. 42, 780-796. doi: 10.1159/000478069

Li, X., Song, Y., Liu, F., Liu, D., Miao, H., Ren, J., et al. (2017a). Long non-coding RNA MALAT1 promotes proliferation. angiogenesis, and immunosuppressive properties of mesenchymal stem cells by inducing VEGF and IDO. J. Cell. Biochem. 118, 2780-2791. doi: 10.1002/jcb.25927

Li, Z., Ruan, Y., Zhang, H., Shen, Y., Li, T., and Xiao, B. (2019c). Tumor-suppressive circular RNAs: mechanisms underlying their suppression of tumor occurrence and use as therapeutic targets. Cancer Sci. 110, 3630-3638. doi: 10.1111/cas. 14211

Ling, Z., Chen, M., Li, T., Qian, Y., and Li, C. (2021). MiR-141-3p downregulation promotes tube formation, migration, invasion and inhibits apoptosis in hypoxia-induced human umbilical vein endothelial cells by targeting Notch2. Reprod. Biol. 21:100483. doi: 10.1016/j.repbio.2021.100483

Lisonkova, S., Sabr, Y., Mayer, C., Young, C., Skoll, A., and Joseph, K. S. (2014). Maternal morbidity associated with early-onset and late-onset preeclampsia. Obstet Gynecol. 124, 771-781. doi: 10.1097/AOG.0000000000000472

Liu, F., Wu, K., Wu, W., Chen, Y., Wu, H., Wang, H., et al. (2018). miR203 contributes to preeclampsia via inhibition of VEGFA expression. Mol. Med. Rep. 17, 5627-5634. doi: 10.3892/mmr.2018.8558

Liu, L., Wang, Y., Fan, H., Zhao, X., Liu, D., Hu, Y., et al. (2012). MicroRNA-181a regulates local immune balance by inhibiting proliferation and immunosuppressive properties of mesenchymal stem cells. Stem. Cells 30, 1756-1770. doi: 10.1002/stem.1156

Liu, S., Xie, X., Lei, H., Zou, B., and Xie, L. (2019). Identification of key circRNAs/lncRNAs/miRNAs/mRNAs and pathways in preeclampsiausing bioinformatics analysis. Med. Sci. Monit. 25, 1679-1693. doi: 10.12659/MSM. 912801

Liu, W., Liu, X., Luo, M., Liu, X., Luo, Q., Tao, H., et al. (2017). dNK derived IFNgamma mediates VSMC migration and apoptosis via the induction ofLncRNA MEG3: A role in uterovascular transformation. Placenta 50, 32-39. doi: 10. 1016/j.placenta.2016.12.023

Liu, X., Chen, H., Kong, W., Zhang, Y., Cao, L., Gao, L., et al. (2017). Downregulated long non-coding RNA-ATB in preeclampsia and its effect on suppressing migration, proliferation, and tube formation of trophoblast cells. Placenta 49, 80-87. doi: 10.1016/j.placenta.2016.12.004

Lockwood, C. J., Yen, C. F., Basar, M., Kayisli, U. A., Martel, M., Buhimschi, I., et al. (2008). Preeclampsia-related inflammatory cytokines regulate interleukin6 expression inhuman decidual cells. Am. J. Pathol. 172, 1571-1579. doi: 10. 2353/ajpath.2008.070629

Long, W., Rui, C., Song, X., Dai, X., Xue, X., Lu, Y., et al. (2016). Distinct expression profiles of lncRNAs between early-onset preeclampsia and preterm controls. Clin. Chim. Acta 463, 193-199. doi: 10.1016/j.cca.2016.10.036

Lu, W., Ma, Y. Y., Shao, Q. Q., Liang, J., Qi, T. T., Huang, Y., et al. (2020). ROS/p53/miR3355p/Sp1 axis modulates the migration and epithelial to mesenchymal transition of JEG3 cells. Mol. Med. Rep. 21, 1208-1216. doi: 10.3892/mmr.2019.10901

Lukiw, W. J. (2013). Circular RNA (circRNA) in Alzheimer's disease (AD). Front. Genet. 4:307. doi: 10.3389/fgene.2013.00307

Luo, L., Ye, G., Nadeem, L., Fu, G., Yang, B. B., Honarparvar, E., et al. (2012). MicroRNA-378a-5p promotes trophoblast cell survival, migration and invasion by targeting Nodal. J. Cell Sci. 125(Pt. 13), 3124-3132.

Luo, R., Shao, X., Xu, P., Liu, Y., Wang, Y., Zhao, Y., et al. (2014). MicroRNA-210 contributes to preeclampsia by downregulating potassium channel modulatory factor 1. Hypertension 64, 839-845. doi: 10.1161/HYPERTENSIONAHA.114. 03530

Luo, R., Wang, Y., Xu, P., Cao, G., Zhao, Y., Shao, X., et al. (2016). Hypoxiainducible miR-210 contributes to preeclampsia via targeting thrombospondin type I domain containing 7A. Sci Rep 6, 19588. doi: 10.1038/srep19588

Lv, Y., Lu, X., Li, C., Fan, Y., Ji, X., Long, W., et al. (2019). miR-145-5p promotes trophoblast cell growth and invasion by targeting FLT1. Life Sci. 239:117008. doi: 10.1016/j.lfs.2019.117008
Lykoudi, A., Kolialexi, A., Lambrou, G. I., Braoudaki, M., Siristatidis, C., Papaioanou, G. K., et al. (2018). Dysregulated placental microRNAs in early and Late onset preeclampsia. Placenta 61, 24-32. doi: 10.1016/j.placenta.2017. 11.005

Ma, Y., Liang, X., Wu, H., Zhang, C., and Ma, Y. (2019). Long noncoding RNA NR_002794 is upregulated in preeclampsia and regulates the proliferation, apoptosis and invasion of trophoblast cells. Mol. Med. Rep. 20, 4567-4575. doi: 10.3892/mmr.2019.10701

Mavreli, D., Lykoudi, A., Lambrou, G., Papaioannou, G., Vrachnis, N., Kalantaridou, S., et al. (2020). Deep sequencing identified dysregulated circulating microRNAs in late onset preeclampsia. In. Vivo. 34, 2317-2324. doi: 10.21873 /invivo. 12044

McLaughlin, K., Zhang, J., Lye, S. J., Parker, J. D., and Kingdom, J. C. (2018). Phenotypes of Pregnant Women Who Subsequently Develop Hypertension in Pregnancy. J. Am. Heart Assoc. 7:14. doi: 10.1161/JAHA.118.009595

Memczak, S., Jens, M., Elefsinioti, A., Torti, F., Krueger, J., Rybak, A., et al. (2013). Circular RNAs are a large class of animal RNAs with regulatory potency. Nature 495, 333-338. doi: 10.1038/nature11928

Motawi, T., Sabry, D., Maurice, N. W., and Rizk, S. M. (2018). Role of mesenchymal stem cells exosomes derived microRNAs; miR-136, miR-494 and miR-495 in pre-eclampsia diagnosis and evaluation. Arch. Biochem. Biophys. 659, 13-21. doi: 10.1016/j.abb.2018.09.023

Mouillet, J. F., Chu, T., Nelson, D. M., Mishima, T., and Sadovsky, Y. (2010). MiR-205 silences MED1 in hypoxic primary human trophoblasts. Faseb. J. 24, 2030-2039. doi: 10.1096/fj.09-149724

Myatt, L. (2010). Review: reactive oxygen and nitrogen species and functional adaptation of the placenta. Placenta 31(Suppl.), S66-S69. doi: 10.1016/j. placenta.2009.12.021

Ou, Y., Zhu, L., Wei, X., Bai, S., Chen, M., Chen, H., et al. (2020). Circular RNA circ_0111277 attenuates human trophoblast cell invasion and migration by regulating miR-494/HTRA1/Notch-1 signal pathway in pre-eclampsia. Cell Death Dis. 11:479. doi: 10.1038/s41419-020-2679-6

Oudejans, C. B., Poutsma, A., Michel, O. J., Thulluru, H. K., Mulders, J., van de Vrugt, H. J., et al. (2016). Noncoding RNA-regulated gain-of-function of STOX2 in finnish pre-eclamptic families. Sci. Rep. 6:32129. doi: 10.1038/ srep32129

Pamudurti, N. R., Bartok, O., Jens, M., Ashwal-Fluss, R., Stottmeister, C., Ruhe, L., et al. (2017). Translation of CircRNAs. Mol. Cell. 66, 9-21. doi: 10.1016/j.molcel. 2017.02.021

Salomon, C., Guanzon, D., Scholz-Romero, K., Longo, S., Correa, P., Illanes, S. E., et al. (2017). Placental exosomes as early biomarker of preeclampsia: potential role of exosomal microRNAs across gestation. J. Clin. Endocrinol. Metab. 102, 3182-3194. doi: 10.1210/jc.2017-00672

Schjenken, J. E., Zhang, B., Chan, H. Y., Sharkey, D. J., Fullston, T., and Robertson, S. A. (2016). miRNA regulation of immune tolerance in early pregnancy. Am. J. Reprod. Immunol. 75, 272-280. doi: 10.1111/aji.12490

Seifeddine, R., Dreiem, A., Blanc, E., Fulchignoni-Lataud, M. C., Le Frere, B. M., Lecuru, F., et al. (2008). Hypoxia down-regulates CCAAT/enhancer binding protein-alpha expression in breastcancer cells. Cancer Res. 68, 2158-2165. doi: 10.1158/0008-5472.CAN-07-1190

Seyom, E., Abera, M., Tesfaye, M., and Fentahun, N. (2015). Maternal and fetal outcome of pregnancy related hypertension in Mettu Karl Referral Hospital. Ethiopia. J. Ovarian Res. 8:10. doi: 10.1186/s13048-015-0135-5

Sheikh, A. M., Small, H. Y., Currie, G., and Delles, C. (2016). Systematic review of micro-rna expression in pre-eclampsia identifies a number of common pathways associated with the disease. PLoS. One 11:e160808. doi: 10.1371/ journal.pone.0160808

Shen, X. Y., Zheng, L. L., Huang, J., Kong, H. F., Chang, Y. J., Wang, F., et al. (2019). CircTRNC18 inhibits trophoblast cell migration and epithelial-mesenchymal transition by regulating miR-762/Grhl2 pathway in pre-eclampsia. RNA Biol. 16, 1565-1573. doi: 10.1080/15476286.2019.1644591

Shi, L., Fisslthaler, B., Zippel, N., Fromel, T., Hu, J., Elgheznawy, A., et al. (2013). MicroRNA-223 antagonizes angiogenesis by targeting betal integrin and preventinggrowth factor signaling in endothelial cells. Circ. Res. 113, 1320-1330. doi: 10.1161/CIRCRESAHA.113.301824

Shi, Z., She, K., Li, H., Yuan, X., Han, X., and Wang, Y. (2019). MicroRNA454 contributes to sustaining the proliferation and invasion of trophoblast 
cells through inhibiting Nodal/ALK7 signaling in pre-eclampsia. Chem. Biol. Interact. 298, 8-14. doi: 10.1016/j.cbi.2018.10.012

Sohlberg, S., Mulic-Lutvica, A., Lindgren, P., Ortiz-Nieto, F., Wikstrom, A. K., and Wikstrom, J. (2014). Placental perfusion in normal pregnancy and early and late preeclampsia: a magnetic resonance imaging study. Placenta 35, 202-206. doi: 10.1016/j.placenta.2014.01.008

Song, J., Li, Y., and An, R. F. (2015). Identification of early-onset preeclampsiarelated genes and microRNAs by bioinformatics approaches. Rep. Sci. 22, 954-963. doi: 10.1177/1933719115570898

Song, X., Rui, C., Meng, L., Zhang, R., Shen, R., Ding, H., et al. (2017). Long noncoding RNA RPAIN regulates the invasion and apoptosis of trophoblast cell lines via complement protein C1q. Oncotarget 8, 7637-7646. doi: 10.18632/ oncotarget. 13826

Sonkar, R., Kay, M. K., and Choudhury, M. P. F. O. S. (2019). Modulates interactive epigenetic regulation in first-trimester human trophoblast cell line HTR-8/SVneo. Chem. Res. Toxicol. 32, 2016-2027. doi: 10.1021/acs.chemrestox. $9 \mathrm{~b} 00198$

Souza, J. P., Gulmezoglu, A. M., Vogel, J., Carroli, G., Lumbiganon, P., Qureshi, Z., et al. (2013). Moving beyond essential interventions for reduction of maternal mortality (the WHO Multicountry Survey on Maternal and Newborn Health): a cross-sectional study. Lancet 381, 1747-1755. doi: 10.1016/S0140-6736(13) 60686-8

Steegers, E. A., von Dadelszen, P., Duvekot, J. J., and Pijnenborg, R. (2010). Pre-eclampsia. Lancet 376, 631-644. doi: 10.1016/S0140-6736(10)60279-6

Stubert, J., Koczan, D., Richter, D. U., Dieterich, M., Ziems, B., Thiesen, H. J., et al. (2014). miRNA expression profiles determined in maternal sera of patients with HELLP syndrome. Hypertens Pregnancy 33, 215-235. doi: 10.3109/10641955. 2013.858743

Sun, K., and Lai, E. C. (2013). Adult-specific functions of animal microRNAs. Nat. Rev. Genet. 14, 535-548. doi: 10.1038/nrg3471

Sun, M., and Kraus, W. L. (2015). From discovery to function: the expanding roles of long noncoding RNAs in physiology and disease. Endocr. Rev. 36, 25-64. doi: 10.1210/er.2014-1034

Tian, J., Liu, Y., Hu, M., Zheng, Y., Xu, P., Zhang, L., et al. (2020). Upregulated LncZBTB39 in pre-eclampsia and its effects on trophoblast invasion and migration via antagonizing the inhibition of miR-210 on THSD7A expression. Eur. J. Obstet. Gynecol. Rep. Biol. 248, 164-171.

Timofeeva, A. V., Gusar, V. A., Kan, N. E., Prozorovskaya, K. N., Karapetyan, A. O., Bayev, O. R., et al. (2018). Identification of potential early biomarkers of preeclampsia. Placenta 61, 61-71. doi: 10.1016/j.placenta.2017.11.011

Tong, J., Yang, J., Lv, H., Lv, S., Zhang, C., and Chen, Z. J. (2018). Dysfunction of pseudogene PGK1P2 is involved in preeclampsia by acting as a competing endogenous RNA of PGK1. Pregnancy Hypertens 13, 37-45. doi: 10.1016/j. preghy.2018.05.003

Tsai, P. Y., Li, S. H., Chen, W. N., Tsai, H. L., and Su, M. T. (2017). Differential miR-346 and miR-582-3p expression in association with selected maternal and fetal complications. Int. J. Mol. Sci. 18:1570. doi: 10.3390/ijms18071570

Wang, C. Y., Tsai, P. Y., Chen, T. Y., Tsai, H. L., Kuo, P. L., and Su, M. T. (2019). Elevated miR-200a and miR-141 inhibit endocrine gland-derived vascular endothelial growth factor expression and ciliogenesis in preeclampsia. J. Physiol. 597, 3069-3083. doi: 10.1113/JP277704

Wang, H., Zhang, L., Guo, X., Bai, Y., Li, Y. X., Sha, J., et al. (2018). MiR195 modulates oxidative stress-induced apoptosis and mitochondrial energy production in human trophoblasts via flavin adenine dinucleotide-dependent oxidoreductase domain-containing protein 1 and pyruvate dehydrogenase phosphatase regulatory subunit. J. Hypertens 36, 306-318. doi: 10.1097/HJH. 0000000000001529

Wang, P., Xue, Y., Han, Y., Lin, L., Wu, C., Xu, S., et al. (2014). The STAT3-binding long noncoding RNA lnc-DC controls human dendritic cell differentiation. Science 344, 310-313. doi: 10.1126/science. 1251456

Wang, Q., Lu, X., Li, C., Zhang, W., Lv, Y., Wang, L., et al. (2019). Down-regulated long non-coding RNA PVT1 contributes to gestational diabetes mellitus and preeclampsia via regulation of human trophoblast cells. Biomed. Pharmacother. 120:109501. doi: 10.1016/j.biopha.2019.109501

Wang, R., Liu, W., Liu, X., Liu, X., Tao, H., Wu, D., et al. (2019). MicroRNA-210 regulates human trophoblast cell line HTR-8/SVneo function by attenuating Notch1 expression: Implications for the role of microRNA-210 in preeclampsia. Mol Reprod Dev 86, 896-907. doi: 10.1002/mrd.23154
Wang, W. T., Ye, H., Wei, P. P., Han, B. W., He, B., Chen, Z. H., et al. (2016). LncRNAs H19 and HULC, activated by oxidative stress, promote cell migration and invasion in cholangiocarcinoma through a ceRNA manner. J. Hematol. Oncol. 9:117. doi: 10.1186/s13045-016-0348-0

Wang, W., Feng, L., Zhang, H., Hachy, S., Satohisa, S., Laurent, L. C., et al. (2012). Preeclampsia up-regulates angiogenesis-associated microRNA (i.e., miR-17, 20a, and -20b) that target ephrin-B2 and EPHB4 in human placenta. J. Clin. Endocrinol. Metab 97, E1051-E1059. doi: 10.1210/jc.2011-3131

Wang, X. Q., Zhou, W. J., Hou, X. X., Fu, Q., and Li, D. J. (2018). Trophoblastderived CXCL16 induces M2 macrophage polarization that in turn inactivates NK cells at the maternal-fetal interface. Cell Mol. Immunol. 15, 1038-1046. doi: 10.1038/s41423-018-0019-x

Wang, Y., Cheng, K., Zhou, W., Liu, H., Yang, T., Hou, P., et al. (2019). miR-141-5p regulate ATF2 via effecting MAPK1/ERK2 signaling to promote preeclampsia. Biomed. Pharmacother. 115:108953. doi: 10.1016/j.biopha.2019.10 8953

Wang, Y., Dong, Q., Gu, Y., and Groome, L. J. (2016). Up-regulation of miR203 expression induces endothelial inflammatory response: potential role in preeclampsia. Am. J. Reprod. Immunol. 76, 482-490. doi: 10.1111/aji.12589

Wang, Y., Zhang, Y., Wang, H., Wang, J., Zhang, Y., Wang, Y., et al. (2014). Aberrantly up-regulated miR-20a in pre-eclampsic placenta compromised the proliferative and invasive behaviors of trophoblast cells by targeting forkhead box protein A1. Int J Biol Sci 10, 973-982. doi: 10.7150/ijbs.9088

Weber, M., Gohner, C., San, M. S., Vattai, A., Hutter, S., Parraga, M., et al. (2016). Unique trophoblast stem cell- and pluripotency marker staining patterns depending on gestational age and placenta-associated pregnancy complications. Cell Adh. Migr. 10, 56-65. doi: 10.1080/19336918.2016.1142035

Wen, Z., Chen, Y., Long, Y., Yu, J., and Li, M. (2018). Tumor necrosis factor-alpha suppresses the invasion of HTR-8/SVneo trophoblast cells through microRNA145-5p-mediated downregulation of Cyr61. Life Sci. 209, 132-139. doi: 10.1016/ j.lfs.2018.08.005

Wu, D., Chen, X., Wang, L., Chen, F., Cen, H., and Shi, L. (2019). Hypoxia-induced microRNA-141 regulates trophoblast apoptosis, invasion, and vascularization by blocking CXCL12beta/CXCR2/4 signal transduction. Biomed. Pharmacother. 116:108836. doi: 10.1016/j.biopha.2019.108836

Wu, H. Y., Wang, X. H., Liu, K., and Zhang, J. L. (2020). LncRNA MALAT1 regulates trophoblast cells migration and invasion via miR-206/IGF-1 axis. Cell Cycle 19, 39-52. doi: 10.1080/15384101.2019.1691787

Wu, J. L., Wang, Y. G., Gao, G. M., Feng, L., Guo, N., and Zhang, C. X. (2019). Overexpression of IncRNA TCL6 promotes preeclampsia progression by regulating PTEN. Eur. Rev. Med. Pharmacol. Sci. 23, 4066-4072. doi: 10. 26355/eurrev_201905_17907

Wu, L., Song, W. Y., Xie, Y., Hu, L. L., Hou, X. M., Wang, R., et al. (2018). miR181a-5p suppresses invasion and migration of HTR-8/SVneo cells by directly targeting IGF2BP2. Cell Death Dis. 9:16. doi: 10.1038/s41419-017-0045-0

Wu, L., Zhou, H., Lin, H., Qi, J., Zhu, C., Gao, Z., et al. (2012). Circulating microRNAs are elevated in plasma from severe preeclamptic pregnancies. Reproduction 143, 389-397. doi: 10.1530/REP-11-0304

Wu, P., van den Berg, C., Alfirevic, Z., O’Brien, S., Rothlisberger, M., Baker, P. N., et al. (2015). Early pregnancy biomarkers in pre-eclampsia: a systematic review and meta-analysis. Int. J. Mol. Sci. 16, 23035-23056. doi: 10.3390/ ijms160923035

Xia, S., Feng, J., Lei, L., Hu, J., Xia, L., Wang, J., et al. (2017). Comprehensive characterization of tissue-specific circular RNAs in the human andmouse genomes. Brief. Bioinform. 18, 984-992. doi: 10.1093/bib/bbw081

Xin, G., Du, J., Liu, M. Y., and Xu, Y. P. (2017). Upregulation of MiR-29b contributes to mesenchymal stem cell dysfunction in patients with severe pre-eclampsia. Int. J. Clin. Exp. Pathol. 10, 10243-10251.

Xu, J., Xia, Y., Zhang, H., Guo, H., Feng, K., and Zhang, C. (2018). Overexpression of long non-coding RNA H19 promotes invasion and autophagy via the PI3K/AKT/mTOR pathways in trophoblast cells. Biomed. Pharmacother. 101, 691-697. doi: 10.1016/j.biopha.2018.02.134

Xu, Y., Lian, Y., Zhang, Y., Huang, S., Zuo, Q., Yang, N., et al. (2018). The long noncoding RNA PVT1 represses ANGPTL4 transcription through binding with EZH2 in trophoblast cell. J. Cell Mol. Med. 22, 1272-1282. doi: 10.1111/jcmm. 13405

Xu, Y., Xia, X., Jiang, Y., Wu, D., Wang, S., Fu, S., et al. (2020). Down-regulated lncRNA AGAP2-AS1 contributes to pre-eclampsia as a competing endogenous 
RNA for JDP2 by impairing trophoblastic phenotype. J. Cell. Mol. Med. 24, 4557-4568. doi: $10.1111 / \mathrm{jcmm} .15113$

Xue, P., Zheng, M., Diao, Z., Shen, L., Liu, M., Gong, P., et al. (2013). miR$155^{*}$ mediates suppressive effect of PTEN 3'-untranslated region on AP-1/NFkappaB pathway in HTR-8/SVneo cells. Placenta 34, 650-656. doi: 10.1016/j. placenta.2013.04.015

Yan, T., Liu, Y., Cui, K., Hu, B., Wang, F., and Zou, L. (2013). MicroRNA-126 regulates EPCs function: implications for a role of miR-126 in preeclampsia. J. Cell. Biochem. 114, 2148-2159. doi: 10.1002/jcb.24563

Yang, S., Li, H., Ge, Q., Guo, L., and Chen, F. (2015). Deregulated microRNA species in the plasma and placenta of patients with preeclampsia. Mol. Med. Rep. 12, 527-534. doi: 10.3892/mmr.2015.3414

Yang, W., Wang, A., Zhao, C., Li, Q., Pan, Z., Han, X., et al. (2016). miR$125 \mathrm{~b}$ enhances IL-8 production in early-onset severe preeclampsia by targeting sphingosine-1-phosphate lyase 1. PLoS One 11:e166940. doi: 10.1371/journal. pone. 0166940

Yang, X., and Guo, F. (2019). miR3423p suppresses cell migration and invasion in preeclampsia by targeting plateletderived growth factor receptor alpha. Mol. Med. Rep. 20, 1772-1780. doi: 10.3892/mmr.2019.10372

Yang, X., Guo, L., Li, H., Chen, X., and Tong, X. (2012). Analysis of the original causes of placental oxidative stress in normal pregnancy and pre-eclampsia: a hypothesis. J. Matern. Fetal. Neonatal. Med. 25, 884-888. doi: 10.3109/ 14767058.2011.601367

Yang, Y., Fan, X., Mao, M., Song, X., Wu, P., Zhang, Y., et al. (2017). Extensive translation of circular RNAs driven by N(6)-methyladenosine. Cell Res. 27, 626-641. doi: 10.1038/cr.2017.31

Yang, Y., Xi, L., Ma, Y., Zhu, X., Chen, R., Luan, L., et al. (2019). The IncRNA small nucleolar RNA host gene 5 regulates trophoblast cell proliferation, invasion, and migration via modulating miR-26a-5p/N-cadherin axis. J. Cell. Biochem. 120, 3173-3184. doi: $10.1002 /$ jcb. 27583

Yoon, J. H., Abdelmohsen, K., and Gorospe, M. (2013). Posttranscriptional gene regulation by long noncoding RNA. J. Mol. Biol. 425, 3723-3730. doi: 10.1016/ j.jmb.2012.11.024

Yu, Y., Wang, L., Gao, M., and Guan, H. (2018). Long non-coding RNA TUG1 regulates the migration and invasion of trophoblast-like cells through sponging miR-204-5p. Clin. Exp. Pharmacol. Physiol. 46, 380-388. doi: 10.1111/14401681.13058

Yuan, Y., Wang, X., Sun, Q., Dai, X., and Cai, Y. (2020). MicroRNA-16 is involved in the pathogenesis of pre-eclampsia via regulation of notch2. J. Cell. Physiol. 235, 4530-4544. doi: 10.1002/jcp.29330

Zhang, L., Li, H., Li, M., Zhang, W., Yang, Z., and Zhang, S. (2020). LRP6 is involved in the proliferation, migration and invasion of trophoblast cells via miR346. Int. J. Mol. Med. 46, 211-223. doi: 10.3892/ijmm.2020.4570

Zhang, L., Qin, D., Hao, C., Shu, X., and Pei, D. (2013). SNX16 negatively regulates the migration and tumorigenesis of MCF-7 cells. Cell. Regen. 2:3. doi: 10.1186/ 2045-9769-2-3

Zhang, M., Muralimanoharan, S., Wortman, A. C., and Mendelson, C. R. (2016). Primate-specific miR-515 family members inhibit key genes in human trophoblast differentiation and are upregulated in preeclampsia. Proc. Natl. Acad. Sci. U.S.A. 113, E7069-E7076. doi: 10.1073/pnas.160784 9113

Zhang, S. S., Kan, X. Q., Liu, P., Yin, L. Z., Li, Q. Y., and Xu, H. Y. (2020). MiR$20 \mathrm{~b}$ is implicated in preeclampsia progression via the regulation of myeloid cell leukemin-1. J. Biol. Regul. Homeost. Agents 34, 1709-1717. doi: 10.23812/20231-A

Zhang, W. M., Cao, P., Xin, L., Zhang, Y., Liu, Z., Yao, N., et al. (2019). Effect of miR-133 on apoptosis of trophoblasts in human placenta tissues via Rho/ROCK signaling pathway. Eur. Rev. Med. Pharmacol. Sci. 23, 10600-10608. doi: 10. 26355/eurrev_201912_19755

Zhang, W., Yang, M., Yu, L., Hu, Y., Deng, Y., Liu, Y., et al. (2020). Long non-coding RNA lnc-DC in dendritic cells regulates trophoblast invasion viapSTAT3-mediated TIMP/MMP expression. Am. J. Reprod. Immunol. 83:e13239. doi: $10.1111 /$ aji.13239

Zhang, W., Zhou, Y., and Ding, Y. (2017). Lnc-DC mediates the over-maturation of decidual dendritic cells and induces the increase in Th1 cells in preeclampsia. Am. J. Reprod. Immunol. 77:e12647. doi: 10.1111/aji.12647
Zhang, Y. G., Yang, H. L., Long, Y., and Li, W. L. (2016). Circular RNA in blood corpuscles combined with plasma protein factor for early prediction of pre-eclampsia. BJOG 123, 2113-2118. doi: 10.1111/1471-0528.13897

Zhang, Y., Cao, L., Jia, J., Ye, L., Wang, Y., Zhou, B., et al. (2019). CircHIPK3 is decreased in preeclampsia and affects migration, invasion, proliferation, and tube formation of human trophoblast cells. Placenta 85, 1-8. doi: 10.1016/j. placenta.2019.07.010

Zhang, Y., Fei, M., Xue, G., Zhou, Q., Jia, Y., Li, L., et al. (2012). Elevated levels of hypoxia-inducible microRNA-210 in pre-eclampsia: new insightsinto molecular mechanisms for the disease. J. Cell Mol. Med. 16, 249-259. doi: 10.1111/j.1582-4934.2011.01291.x

Zhang, Y., Qu, L., Ni, H., Wang, Y., Li, L., Yang, X., et al. (2020). Expression and function of lncRNA MALAT1 in gestational diabetes mellitus. Adv. Clin. Exp. Med. 29, 903-910. doi: 10.17219/acem/121524

Zhang, Y., Zhang, X. O., Chen, T., Xiang, J. F., Yin, Q. F., Xing, Y. H., et al. (2013). Circular intronic long noncoding RNAs. Mol. Cell. 51, 792-806. doi: 10.1016/j.molcel.2013.08.017

Zhang, Y., Zou, Y., Wang, W., Zuo, Q., Jiang, Z., Sun, M., et al. (2015). Downregulated long non-coding RNA MEG3 and its effect on promoting apoptosis and suppressing migration of trophoblast cells. J. Cell Biochem. 116, 542-550. doi: $10.1002 /$ jcb. 25004

Zhang, Z., Yang, T., and Xiao, J. (2018). Circular RNAs: promising biomarkers for human diseases. Ebiomedicine 34, 267-274. doi: 10.1016/j.ebiom.2018.07.036

Zhao, G., Miao, H., Li, X., Chen, S., Hu, Y., Wang, Z., et al. (2016). TGFbeta3-induced miR-494 inhibits macrophage polarization via suppressing PGE2 secretion in mesenchymal stem cells. FEBS Lett. 590, 1602-1613. doi: 10.1002/ 1873-3468.12200

Zhao, Y. H., Liu, Y. L., Fei, K. L., and Li, P. (2020). Long non-coding RNA HOTAIR modulates the progression of preeclampsia through inhibiting miR-106 in an EZH2-dependent manner. Life Sci. 253:117668. doi: 10.1016/j.lfs.2020.117668

Zhao, Z. M., and Jiang, J. (2018). Lowly expressed EGFR-AS1 promotes the progression of preeclampsia by inhibiting the EGFR-JAK/STAT signaling pathway. Eur. Rev. Med. Pharmacol. Sci. 22, 6190-6197. doi: 10.26355/eurrev_ 201810_16024

Zhou, W., Wang, H., Wu, X., Long, W., Zheng, F., Kong, J., et al. (2018). The profile analysis of circular RNAs in human placenta of preeclampsia. Exp. Biol. Med. (Maywood) 243, 1109-1117. doi: 10.1177/1535370218813525

Zhu, H., Niu, X., Li, Q., Zhao, Y., Chen, X., and Sun, H. (2020). Circ_0085296 suppresses trophoblast cell proliferation, invasion, and migration via modulating miR-144/E-cadherin axis. Placenta 97, 18-25. doi: $10.1016 /$ j.placenta.2020.06.002

Zhu, H., Zhou, X., Chang, H., Li, H., Liu, F., Ma, C., et al. (2015). CCAT1 promotes hepatocellular carcinoma cell proliferation and invasion. Int. J. Clin. Exp. Pathol. 8, 5427-5434.

Zhu, X. M., Han, T., Sargent, I. L., Yin, G. W., and Yao, Y. Q. (2009). Differential expression profile of microRNAs in human placentas from preeclamptic pregnancies vs normal pregnancies. Am. J. Obstet. Gynecol. 200:661. doi: 10. 1016/j.ajog.2008.12.045

Zou, Y., Jiang, Z., Yu, X., Sun, M., Zhang, Y., Zuo, Q., et al. (2013). Upregulation of long noncoding RNA SPRY4-IT1 modulates proliferation, migration,apoptosis, and network formation in trophoblast cells HTR-8SV/neo. PLoS One 8:e79598. doi: 10.1371/journal.pone.0079598

Zuo, Q., Huang, S., Zou, Y., Xu, Y., Jiang, Z., Zou, S., et al. (2016). The Lnc RNA SPRY4-IT1 modulates trophoblast cell invasion and migration by affecting the epithelial-mesenchymal transition. Sci. Rep. 6:37183. doi: 10.1038/srep37183

Conflict of Interest: The authors declare that the research was conducted in the absence of any commercial or financial relationships that could be construed as a potential conflict of interest.

Copyright (c) 2021 Chen, Yu, Jiang, Xia and Chen. This is an open-access article distributed under the terms of the Creative Commons Attribution License (CC BY). The use, distribution or reproduction in other forums is permitted, provided the original author(s) and the copyright owner(s) are credited and that the original publication in this journal is cited, in accordance with accepted academic practice. No use, distribution or reproduction is permitted which does not comply with these terms. 